TI 2015-096/VI

Tinbergen Institute Discussion Paper

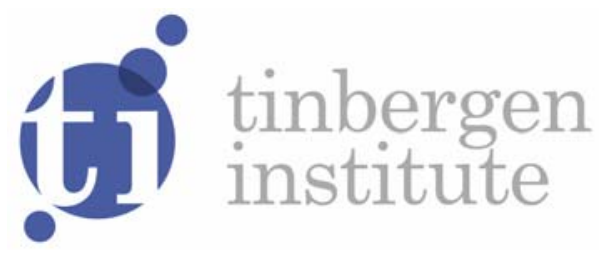

\title{
Trade, Factor Mobility and the Extent of Economic Integration: \\ Theory and Evidence
}

\author{
Irena Mikolajun
}

Jean-Marie Viaene

Erasmus School of Economics, Erasmus University Rotterdam, and Tinbergen Institute, the Netherlands. 
Tinbergen Institute is the graduate school and research institute in economics of Erasmus University Rotterdam, the University of Amsterdam and VU University Amsterdam.

More TI discussion papers can be downloaded at http://www.tinbergen.nl

Tinbergen Institute has two locations:

Tinbergen Institute Amsterdam

Gustav Mahlerplein 117

1082 MS Amsterdam

The Netherlands

Tel.: +31(0)205251600

Tinbergen Institute Rotterdam

Burg. Oudlaan 50

3062 PA Rotterdam

The Netherlands

Tel.: +31(0)10 4088900

Fax: $+31(0) 104089031$

Duisenberg school of finance is a collaboration of the Dutch financial sector and universities, with the ambition to support innovative research and offer top quality academic education in core areas of finance.

DSF research papers can be downloaded at: http://www.dsf.nl/

Duisenberg school of finance

Gustav Mahlerplein 117

1082 MS Amsterdam

The Netherlands

Tel.: +31(0)20 5258579 


\title{
Trade, Factor Mobility and the Extent of Economic Integration: Theory and Evidence
}

\author{
Irena Mikolajun* Jean-Marie Viaene $^{\dagger}$
}

August 11, 2015

\begin{abstract}
The Middle East was once seen as a medieval great globalized force. Nowadays it shows one of the lowest intra-regional trade in the world and therefore it is claimed that the region is poorly integrated. Yet, with the steady flow of workers across national borders of the Middle East is this conjecture correct? To answer this question the paper develops an integration benchmark which consists of the steady state production equilibrium characterized by free trade and perfect factor mobility. We apply metrics to measure the distance between this benchmark and the data and compare three different regions of the world (EU, Latin America and Middle East). We find that, despite large differences in trade patterns, measures of economic integration in 2009 are remarkably close across regions. For example, we calculate that economic integration in the Middle East is just $2.4 \%$ below that of the European Union.
\end{abstract}

JEL Classification: E13, F15, F21, F4, O11, O53, O54

Keywords: economic integration, Euclidean distance, factor shares, international migration

${ }^{*}$ Tinbergen Institute, 3000 DR Rotterdam, The Netherlands; Tel.: +31-6-49974434; E-mail: mikolajun@ese.eur.nl, irena.mikolajun@gmail.com

${ }^{\dagger}$ Erasmus School of Economics, 3000 DR Rotterdam, The Netherlands; Tel.: +31-10-4081397; Fax: +31-10-4089161; E-mail: viaene@ese.eur.nl 


\section{Introduction}

The literature has demonstrated the benefits of international trade for the growth experience of open economies (Harrison and Rodríguez-Clare, 2009). Particularly, integration among economies plays an important role in that it increases the long-run rate of growth. For example, the essential idea of Rivera-Batiz and Romer (1991) is that integration stimulates the worldwide exploitation of increasing returns to scale in research and development. Factor mobility is also a powerful instrument in the allocation of resources and some regions of the world have fewer barriers to labour mobility than to goods trade. Mundell (1957), in his formal analysis of the interaction between the international flow of goods and factors, shows that if factors are internationally mobile, in the extreme form, trade in goods will cease, which implies that goods trade and factor flows are substitutes. The important assumptions are those that ensure factor price equalization, including incomplete specialization. However, Hanson (2010) addresses this conjecture and shows cases of complementarity instead. Hence, the way international factors directly influence the allocation of resources is an empirical question. Taken together these strands of the literature point to the need to construct a comprehensive measure of economic integration among a specific group of countries that goes beyond trade statistics and includes both goods and factor flows. This paper develops such a measure and proposes ways to apply it to different regions of the world.

Let us consider the Middle East, for example. The region comprises a wide and heterogeneous group of countries. Significant variations in per capita incomes, different current account positions influenced largely by the possession of natural resources, highly unequal endowments of production factors contribute to this heterogeneity. On the other hand, common religion and common language in most economies introduce a solid common ground. ${ }^{1}$ Nowadays, the region shows by far the lowest intra-regional trade level in the world and a low involvement in the world trading system. For these reasons, it is often claimed to be a large underachiever in trade and poorly integrated (World Bank, 2004). However, the steady flow of people across national borders have significantly contributed to migrants' remittances and to output growth thanks to their size and stability (Bugamelli and Paterno, 2011). Since the effects of increased factor mobility are not universal, the following questions are often raised: $(i)$ With barriers to trade but labour mobile across countries how valid is the conjecture that the Middle East is poorly integrated? (ii) How are integration measures evolving over time and how do they compare to other parts of the

\footnotetext{
${ }^{1}$ Moreover, the region was once an example of high and successful economic integration. In their discussion of the Golden Age of Islam (8th - 13th centuries), Findlay and O'Rourke (2007) mention that the exchange in goods, techniques, ideas as well as movement of people was flourishing. Arab trade routes stretched from West Africa to China and India and long distance travel of final goods and raw materials took place. However, a geopolitical fragmentation of the Middle East contributed to the sunset of the Golden Age of Islam and eroded its contribution to science and trade. It is claimed that the region has never achieved the same nor even close degree of economic integration.
} 
world? The objective of this paper is to address these issues both formally and empirically.

Several research institutes compile indicators of globalization for countries and the world. Recognizing that the dynamics of globilization is a complex matter, indices give weight to economic, social and political variables (see, for example, the KOF index). Though useful these indicators assess the extent by which economies are part of the globalized world at a particular moment in time. However, they do not indicate how far these economies are in their integration process because the limits to integration are not specified. Given this, a challenge of this paper is to develop an integration benchmark which consists of a steady state equilibrium characterized by (1) free trade and (2) perfect mobility of both physical and human capital. Metrics are then developed to measure the distance between this benchmark and the observed equilibrium characterized by barriers to international trade and to factor mobility. These metrics allow for comparison of integration over time and across regions.

There is a vast literature that has contributed to our understanding of the various dimensions of international labour migration. For example, recent topics include interest groups and immigration (Facchini et al., 2011), policy interactions between host and source countries facing skilled-worker migration (Djajić et al., 2012) and temporary low-skilled migration and welfare (Djajić, 2014). Closer to our work, Borjas (2001) tests the hypothesis of immigration being "the grease on the wheels" of the labour market. Likewise, in our model migration leads to greater labour market efficiency in that the geographic sorting of migrants ensures that the value marginal products of labour are equalized across countries. Labour migration can also alter the market for physical capital and aggregate production. Galor and Stark (1990) show that the probability of return migration results in migrants saving more than comparable local residents. Kugler and Rapoport (2007), Javorcik et al. (2011) find that the presence of migrants in the US causes US foreign direct investment in the migrants' countries of origin. In contrast, calibrating a dynamic general equilibrium model to match Canadian data over 1861 - 1913 Wilson (2003) shows that labour force growth through immigration is responsible for up to three quarters of the rise in the foreign capital inflows. Similarly, the driving force behind international capital flows in our framework is the impact of international labour migration on the value of marginal products of physical capital.

Our analysis focuses on the distribution of output and the stocks of productive factors within a particular region. Particularly, the variables of interest are country output shares of regional output and country factor shares of regional factor supplies which have been shown to be important both theoretically and empirically (see, for example, Helpman and Krugman, 1985; Bowen et al., 1987; Viaene and Zilcha, 2002). In this paper, shares are assumed to behave randomly and their path to be described by (possibly correlated) reflected geometric Brownian motions with a lower and upper bound. A random process 
modeled as a Brownian motion is one approach out of many, but it has the property of being parsimonious in terms of number of parameters. A lower bound is justified since nowadays countries are unlikely to disappear; an upper bound matters as the sum of shares must be one. Given this, starting from some initial conditions, we derive the steady state distribution of shares across member countries of a particular region.

Some features of our model have been analyzed before in other frameworks. Particularly, there has been a rapidly growing literature on the empirical measurement of economic integration. Caselli and Feyer (2007) find that, despite large differences in capital-labour ratios, marginal products of capital are close across countries. ${ }^{2}$ As Lucas (1990) originally pointed out one of the explanations for this outcome is that poor countries also have lower total factor productivity (TFP) and lower endowments of factors complementary to physical capital such as human capital. Other studies, e.g. Riezman et al. (2011), assess how far the world economy is between autarky and free trade and develop methodologies to answer the question using a global general equilibrium model. Riezman et al. (2013) discuss metrics of globalization for individual economies as distance measures between fully integrated and trade restricted equilibria. Bowen et al. (2011) test empirically the properties of the distribution of outputs and stocks of productive factors expected to arise between members of a fully integrated economic area. ${ }^{3}$

An objective of our empirical section is to apply measures of economic integration to three groups of countries. Particularly, we contrast the Middle East with the European Union (specifically the 15 original countries or EU-15), which we consider to be a benchmark of "complete" integration, and with Latin America (specifically the Latin American Integration Association or ALADI), a control group of countries at about the same stage of economic development. Empirical tests performed by Bowen et al. (2011) show that EU integration rose from the 1960s to equal that of US states by 2000. A comparison to EU integration is also preferred due to limitations on sourcing data for US state physical capital stocks. ${ }^{4}$ The other control group, ALADI, is the largest Latin American trading bloc that includes most of the sovereign states of Latin America. Their income per capita is similar to the Middle East (on average if weighted by population) but their degree of integration, suggested by intra-regional trade and memberships in trade agreements, is seemingly higher.

\footnotetext{
${ }^{2}$ Though marginal products of capital (MPK) are generally close, differences are observed across countries of the Middle East. Implied estimates of MPK are 0.09 in Jordan and Morocco, 0.07 in Tunisia, 0.05 in Egypt and 0.03 in Algeria (their Table II, last column).

${ }^{3}$ The evolution of integration over time can also be assessed by focussing on prices of homogeneous goods and homogeneous assets assuming that price differentials reflect market frictions and/or lack of arbitrage. For example, Volosovych (2011) looks at patterns of nominal and real long-term bonds; Uebele (2013) analyzes wheat prices in Europe and the USA.

${ }^{4}$ Annual estimates of physical capital stocks per states have to be approximated from estimates of the aggregate US physical capital stock in each of nine one-digit industrial sectors that comprise aggregate activity.
} 
Assuming fully integrated goods and factor markets and comparing dynamic equilibrium paths, we obtain the following results: $(i)$ Using variable elasticity production functions, we obtain an equality between output and factor shares of a given economy. Particularly, each member's share of an area's total output will equal its share of the area's total stock of physical capital and of human capital; (ii) We derive the steady state distribution of shares when a lower and an upper bound are imposed on their evolution. This extends Gabaix (1999) result for the expected distribution of city shares of a nation's population; (iii) Using the properties of this distribution, we derive theoretical shares of each country's output and factors in the grand total. This solution is uniquely determined as a function of the number of countries in the area and of the parameters of the reflected geometric Brownian motion; (iv) Using the metrics of distance available in the literature, we show that economic integration in the Middle East is incomplete but in 2009 only $2.4 \%$ below that of the European Union; $(v)$ More generally, we find that despite large differences in trade patterns, measures of economic integration are remarkably close across regions.

The paper is organized as follows. Section 2 defines our geographic units and discusses the respective patterns of trade and factor movements. Section 3 outlines the model and establishes a key theoretical result; in addition, it describes the data and discusses the empirical method used. Section 4 derives the steady state equilibrium distribution of shares and applies Maximum Likelihood on available data. Section 5 includes the derivation of the steady state distribution of shares and the computation of integration measures for each region. Section 6 explores the quantitative implications of our results by computing, for example, how large human capital flows in the Middle East should be in order to achieve complete integration. Section 7 concludes. The Appendix contains a detailed description of the data sources and methods.

\section{Patterns of Trade and Factor Movements}

\subsection{Defining Geographic Units}

The Middle East is not a uniquely defined economic region. Although as a rule religion and geographical borders serve as a guideline for classification, definitions range from one study to another and are often adopted to meet study specific goals. There are no standards either available in the definitions used by different organizations. Table 1 provides a summary of countries classified as the Middle East and North Africa for the three international organizations that are also the main data sources.Among the four columns we select the definition of the International Monetary Fund (IMF) as it gives a better data coverage for the purpose of our analysis. The definition includes most of the Arab World countries as the World Bank defines but augmented by Iran. We exclude 
Table 1: The definitions of the Middle East.

\begin{tabular}{|c|c|c|c|c|}
\hline Country & $\begin{array}{c}\text { IMF } \\
\text { (Middle East and } \\
\text { North Africa) }\end{array}$ & $\begin{array}{c}\text { World Bank } \\
\text { (Middle East and } \\
\text { North Africa) }\end{array}$ & $\begin{array}{l}\text { World Bank } \\
\text { (Arab World) }\end{array}$ & $\begin{array}{c}\text { WTO } \\
\text { (Middle East) }\end{array}$ \\
\hline Algeria & $\checkmark$ & $\checkmark$ & $\checkmark$ & \\
\hline Bahrain & $\checkmark$ & $\checkmark$ & $\checkmark$ & $\checkmark$ \\
\hline Comoros & & & $\checkmark$ & \\
\hline Djibouti & $\checkmark$ & $\checkmark$ & $\checkmark$ & \\
\hline Egypt & $\checkmark$ & $\checkmark$ & $\checkmark$ & \\
\hline Iran & $\checkmark$ & $\checkmark$ & & $\checkmark$ \\
\hline Iraq & $\checkmark$ & $\checkmark$ & $\checkmark$ & $\checkmark$ \\
\hline Israel & & $\checkmark$ & & $\checkmark$ \\
\hline Jordan & $\checkmark$ & $\checkmark$ & $\checkmark$ & $\checkmark$ \\
\hline Kuwait & $\checkmark$ & $\checkmark$ & $\checkmark$ & $\checkmark$ \\
\hline Lebanon & $\checkmark$ & $\checkmark$ & $\checkmark$ & $\checkmark$ \\
\hline Libya & $\checkmark$ & $\checkmark$ & $\checkmark$ & \\
\hline Malta & & $\checkmark$ & & \\
\hline Mauritania & $\checkmark$ & & $\checkmark$ & \\
\hline Morocco & $\checkmark$ & $\checkmark$ & $\checkmark$ & \\
\hline Oman & $\checkmark$ & $\checkmark$ & $\checkmark$ & $\checkmark$ \\
\hline Qatar & $\checkmark$ & $\checkmark$ & $\checkmark$ & $\checkmark$ \\
\hline Saudi Arabia & $\checkmark$ & $\checkmark$ & $\checkmark$ & $\checkmark$ \\
\hline Somalia & & & $\checkmark$ & \\
\hline Sudan & $\checkmark$ & & $\checkmark$ & \\
\hline Syria & $\checkmark$ & $\checkmark$ & $\checkmark$ & $\checkmark$ \\
\hline Tunisia & $\checkmark$ & $\checkmark$ & $\checkmark$ & \\
\hline United Arab Emirates & $\checkmark$ & $\checkmark$ & $\checkmark$ & $\checkmark$ \\
\hline West Bank and Gaza & & $\checkmark$ & $\checkmark$ & \\
\hline Yemen & $\checkmark$ & $\checkmark$ & $\checkmark$ & $\checkmark$ \\
\hline
\end{tabular}

Notes: $(i)$ World Bank definition of the Arab World coincides with the list of member states of the League of Arab States, a regional organization consisting mainly of Arabic speaking countries; (ii) A number of subregions exist within the Middle East and North Africa: Arab Maghreb Union (Algeria, Libya, Mauritania, Morocco, Tunisia), Mashreq (Iraq, Israel, Jordan, Kuwait, Lebanon, Syria), Gulf Countries (Bahrain, Kuwait, Oman, Qatar, Saudi Arabia, United Arab Emirates). Several studies (Ekanayake and Ledgerwood, 2009; Al-Atrash and Yousef, 2000) documented significant difference with respect to intrasubregional trade. 
Djibouti due to the scarce availability of data. Our definition of the Middle East therefore, that we also call MENA in shorthand notation, comprises 19 economies in the region and covers a geographic area that extends from Iran to the east and Morocco to the west.

EU-15 includes the 15 members of the European Union as of January 1, 1995, namely: Austria, Belgium, Denmark, Finland, France, Germany, Greece, Ireland, Italy, Luxembourg, Netherlands, Portugal, Spain, Sweden and United Kingdom.

ALADI, a Spanish acronym for the Latin American Integration Association (Asociación Latinoamericana de Integración), includes the following 14 countries: Argentina, Bolivia, Brazil, Chile, Colombia, Cuba, Ecuador, Mexico, Nicaragua, Panama, Paraguay, Peru, Uruguay and Venezuela.

\subsection{Comparative Review of Selected Indicators}

Table 2 reviews a number of indicators that are important for our analysis. They characterize each region's position in the world economy and give answers to questions like: In comparison to EU and Latin America does the Middle East really display a high level of labour mobility? Is it true that it is less involved in the world economy? ${ }^{5}$

From Table 2 it emerges that international migrants in the Middle East represent on average $6.9 \%$ of the population. This average is lower than in the EU (9.8\%) but it hides a wider cross-country variation. Though the stock of international migrants is only $0.2 \%$ in Morocco, it is much larger in the Gulf States (86.8\% in Qatar, $84.1 \%$ in Kuwait, etc.). Latin American countries have a low base of foreigners in their societies.

The importance of international migration can be further substantiated by the bilateral migration matrix compiled by Özden et al. (2011) for the period 1960 - 2000. The systematic publication of the latter has been discontinued till 2010. Nevertheless, in that year, what we learn from Table 2, is that $27.6 \%$ of inflows of international migrants into EU-15 originate from within the region against $49.1 \%$ in Latin America and $30.6 \%$ in the Middle East. In contrast, the intra-regional outflow of nationals is $57 \%$ in the EU-15, reflecting the notional free mobility of workers and persons within the region. These percentages are lower for the other two regions, mainly due to the attraction of Northern America. Exploiting bilateral mobility data even further, it turns out that Egypt is the top source country in the Middle East with 3.7 million nationals living abroad. The top migration corridor within the region is Egypt having 1 million nationals living in Saudi Arabia. The top migration corridor into the Middle East includes India having 2.2 million persons being in the United Arab Emirates. This is little compared to the world's largest corridor, the 12.2 million Mexicans living in the US (World Bank, 2011).

\footnotetext{
${ }^{5} \mathrm{~A}$ more exhaustive description of the data can be found on the EU website (http://ec.europa.eu/trade/), the ALADI website (www.aladi.org) and World Bank (2004).
} 
Table 2: Selected summary statistics.

\begin{tabular}{llll}
\hline \hline Statistics & EU-15 & $\begin{array}{l}\text { Latin American } \\
\text { Integration } \\
\text { Association }\end{array}$ & $\begin{array}{l}\text { Middle East } \\
\text { and North } \\
\text { Africa }\end{array}$ \\
\hline \hline $\begin{array}{l}\text { Stock of migrants } \\
\text { (2005, \% of population) }\end{array}$ & & & \\
$\quad \begin{array}{l}\left.\text { Region }{ }^{(}\right) \\
\quad \text { Max }\end{array}$ & 9.8 & 0.7 & 6.9 \\
$\quad 33.6$ (Luxembourg) & 3.9 (Argentina) & 86.8 (Qatar) \\
$\quad$ Min & 3.3 (Finland) & 0.1 (Cuba) & 0.2 (Morocco) \\
\hline $\begin{array}{l}\text { Inflow of migrants } \\
\text { (2010, \% coming from region) }\end{array}$ & 27.6 & 49.1 & 30.6 \\
$\begin{array}{l}\text { Outflow of nationals } \\
\text { (2010, \% heading to region) }\end{array}$ & 57.0 & 23.3 & 32.5 \\
\hline $\begin{array}{l}\text { Intra-regional trade } \\
\text { (2009, \% of total trade) }\end{array}$ & 64.9 & 18.8 & 12.4 \\
WTO participation & & & 12 \\
$\quad \begin{array}{l}\text { Members } \\
\quad \text { Observers }\end{array}$ & 15 & 14 & 8 \\
Average participation in & 35 & 0 & 3 \\
regional trade agreements & & & \\
\hline \hline
\end{tabular}

Notes: (i) Euro area average is taken for EU-15, average of developing countries of Latin America and Carribean is taken for ALADI and Arab World average is taken for MENA; (ii) Observers are: Algeria, Iran, Iraq, Lebanon, Lybia, Syria, Sudan and Yemen; (iii) This corresponds to the average number of regional trade agreements notified to the GATT/WTO and in force.

Source: Own calculations based on World Bank and WTO.

This pattern of international migration stocks is also reflected in the countries' balance of payments through remittances from abroad. Remittances paid from the Gulf Sates make the Gulf region one of the most remitting regions in the world (Naufal, 2011). High per capita income countries such as Oman and Kuwait are major payers of remittances in the region (see Figure 1). Their net remittances amount to about $11 \%$ of their GDP in 2009. On the other hand, Jordan, Yemen, Morocco, Egypt and other lower income and labour abundant economies have been repeated receivers of remittances throughout the last decade. Importantly, the outflow and the inflow of remittances in the Middle East has been very close in value till the Gulf war in 1990, suggesting that remittances were mostly intra-regional. As Naufal (2011) points out, however, after the Gulf war a systematic replacement of Arab workers by cheaper workers from the Indian subcontinent took place, which resulted in a large share of remittances flowing to Asian countries. Though remittances to the Middle East economies diminished since then, yet they remain substantial and illustrate the mutual benefits of labour mobility in the region. The pattern is very different in Latin America. The majority of countries are net receivers of remittances in 2009 (see Figure 1) and although several countries are net payers their net remittances do 
not even reach $1 \%$ of their GDP. ${ }^{6}$

Figure 1: Net workers' remittances to GDP in MENA (left) and ALADI (right).
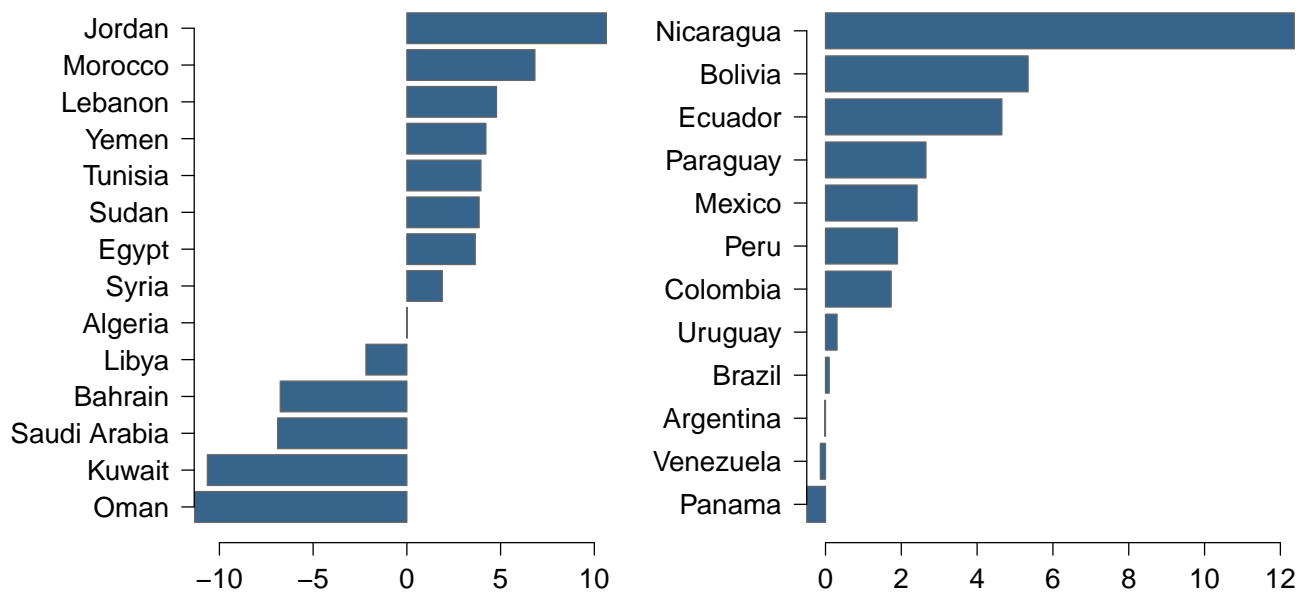

Notes: (i) In percent; (ii) Year 2009; (iii) Current prices.

Source: Own calculations based on IMF Balance of Payments Statistics and World Bank.

It is a commonly held view that trade is a crucial instrument to achieve greater integration. Regions that demonstrate low trade performance are therefore often classified as poorly integrated. Intra-regional trade in the Middle East in 2009 is $12.4 \%$ (see Table 2). This is lower than intra-regional trade in the EU (64.9\%) and Latin America (18.8\%). Ethnic conflicts, protectionism, similar comparative advantages and better product quality outside the region are reasons frequently invoked for this low percentage (see, e.g., Romagnoli and Mengoni, 2009). Standard trade openness indicators, however, remain considerably high even if fuel exports are excluded (see Table 3 ). ${ }^{7}$ This is basically due to high imports in the Middle East that are largely financed by high oil revenues.

Table 2 reveals also that the EU and Latin America are regions that are part of the global system in that all countries are members of the WTO and are participants of several regional trade agreements (RTAs). In contrast only 12 Middle East countries are WTO

\footnotetext{
${ }^{6}$ Another indicator of factor mobility is the ratio of nominal GNI to GDP. This ratio in 2009 fluctuates between 87.53 for Bahrain and 110.38 for Kuwait. As data suggest almost half of the countries in the Middle East are net receivers of factor income from abroad with a GNI to GDP ratio being above 100. Kuwait and Saudi Arabia are also countries receiving high flows of investment income from abroad (see IMF BOPS and World Bank). GNI exceeds GDP also for a number of labour abundant countries like Jordan and Lebanon. The difference here, however, stems not from investment income but from sizeable income of nationals employed abroad. In contrast, for all countries of Latin America GNI never exceeds GDP meaning that countries are net payers of factor income to the rest of the world: while there is a net inflow of remittances into the region there is a larger net outflow of investment income. This comes at no surprise as production of multinationals is widespread in the region while relatively few local firms have subsidiaries abroad.

${ }^{7} 74.9 \%$ of total MENA exports in 2009 were fuel exports (this percentage is computed using 2009 World Bank data on fuel exports of each MENA economy with the exeption of Iran and Mauritania, for which a 2010 figure was taken due to unavailability of 2009 data and United Arab Emirates, for which a 2008 figure was taken).
} 
Table 3: Merchandise trade in MENA.

\begin{tabular}{|c|c|c|c|c|c|}
\hline Country & $\begin{array}{l}\text { Imports } \\
(\% \text { GDP })\end{array}$ & $\begin{array}{l}\text { Exports } \\
(\% \text { GDP }) \\
\end{array}$ & Openness & $\begin{array}{c}\text { Non-fuel exports } \\
(\% \text { GDP })\end{array}$ & $\begin{array}{c}\text { Openness } \\
\text { (excl. fuel exports) }\end{array}$ \\
\hline & $(1)$ & $(2)$ & $(1)+(2)$ & $(3)$ & $(1)+(3)$ \\
\hline Algeria & 27.95 & 32.15 & 60.10 & 0.74 & 28.69 \\
\hline Bahrain & 36.42 & 57.65 & 94.07 & 18.01 & 54.43 \\
\hline Egypt & 23.78 & 12.20 & 35.99 & 8.67 & 32.46 \\
\hline $\operatorname{Iran}^{(2006)}$ & 18.29 & 34.55 & 52.85 & 5.95 & 24.24 \\
\hline Iraq & 56.75 & 64.31 & 121.07 & 0.89 & 57.64 \\
\hline Jordan & 56.74 & 25.41 & 82.14 & 25.26 & 82.00 \\
\hline Kuwait & 18.58 & 47.45 & 66.03 & 3.22 & 21.81 \\
\hline Lebanon & 47.46 & 11.99 & 59.45 & 11.93 & 59.39 \\
\hline Libya ${ }^{(1998)}$ & 20.06 & 24.44 & 44.49 & 1.81 & 21.86 \\
\hline Mauritania $^{(2010)}$ & 50.11 & 55.90 & 106.01 & 55.90 & 106.01 \\
\hline Morocco & 36.17 & 15.46 & 51.63 & 15.10 & 51.27 \\
\hline Oman & 38.27 & 59.00 & 97.27 & 12.37 & 50.64 \\
\hline Qatar & 25.35 & 41.70 & 67.05 & 11.34 & 36.69 \\
\hline Saudi Arabia & 25.64 & 51.61 & 77.25 & 6.41 & 32.05 \\
\hline Sudan & 17.74 & 14.92 & 32.66 & 1.18 & 18.92 \\
\hline Syria $^{(2008)}$ & 34.43 & 29.31 & 63.74 & 18.00 & 52.43 \\
\hline Tunisia & 43.88 & 33.19 & 77.07 & 28.66 & 72.54 \\
\hline $\begin{array}{l}\text { United Arab } \\
\text { Emirates }^{(2008)}\end{array}$ & 56.22 & 75.99 & 132.20 & 26.73 & 82.95 \\
\hline Yemen & 34.84 & 23.74 & 58.58 & 1.85 & 36.69 \\
\hline MENA & 32.61 & 42.72 & 75.33 & 11.00 & 43.61 \\
\hline
\end{tabular}

Notes: $(i)$ The data corresponds to year 2009 if not mentioned otherwise in the superscript of a country name; (ii) Fuel export comprises a third section of a Standard International Trade Classification (SITC 3 ). Thus, fuel export data include not only crude oil, but also coal, natural gas, non-crude oil and other mineral fuels as SITC 3 defines.

Source: Own calculations based on World Bank World Developments Indicators.

members while the remaining 8 are observers. A very limited number of multilateral RTAs exist within the region. Intra-regional trade is being promoted through the Gulf Cooperation Council (GCC, a customs union comprising Bahrain, Kuwait, Oman, Qatar, Saudi Arabia and UAE), the Pan-Arab Free Trade Area (PAFTA, a free trade area including all the MENA countries except Iran and Mauritania) and trade partnerships with Europe (Euro-Mediterranean trade agreements). A significant subset of countries also takes part in the Global System of Trade Preferences among Developing Countries. Altogether, the average participation in trade agreements per country is 3 in contrast to the EU average of 35 and the Latin American average of 8. 


\section{Equality of Output and Factor Shares}

Given this background the analysis of this section focuses on how the distribution of output and stocks of productive factors whould look like if an economic area were characterized by fully integrated goods and factor markets. Particularly, we show the importance of each member's share of an area's total output and its share of the area's total stock of physical capital and of human capital, concepts which have been shown to be important both theoretically and empirically. Particularly, human capital is the factor complementary with physical capital, as it is one of Lucas' major explanations for his puzzle (Lucas, 1990).

\subsection{The Economic Framework}

We consider an economic area consisting of $N$ countries. Each member is assumed to produce a single homogenous good by means of a constant return to scale, but variable elasticity of substitution (VES) production function, proposed by Revankar (1971). The function, which is a generalized Cobb-Douglas production function, reads:

$$
Y_{n t}=\gamma K_{n t}^{1-\delta \rho}\left(H_{n t}+(\rho-1) K_{n t}\right)^{\delta \rho},
$$

where $Y_{n t}, K_{n t}, H_{n t}$ denote output, physical capital and human capital respectively, $n=$ $1, \ldots, N$ is a country, $t=1, \ldots, T$ a time index. Parameter values satisfy $\gamma>0,0<\delta<1$, $0<\delta \rho<1$. The corresponding share of human capital in total output is $\delta \rho[1+(\rho-$ 1) $\left.\frac{K_{n t}}{H_{n t}}\right]^{-1}$, decreasing in $\rho$ and $K_{n t} / H_{n t}$. The elasticity of substitution $\sigma$ depends linearly on the physical-to-human capital ratio:

$$
\sigma=1+\frac{\rho-1}{1-\delta \rho} \frac{K_{n t}}{H_{n t}}
$$

When $\rho=1$ the VES function reduces to the Cobb-Douglas function with a unitary elasticity of substitution $(\sigma=1)$. We assume $\sigma>0$ which implies that the humanto-physical capital ratio is such that $\frac{H_{n t}}{K_{n t}}>\frac{1-\rho}{1-\delta \rho}$. The function spelled out in (1) is therefore different from the constant elasticity of substitution production function in that the elasticity of substitution implied by the VES production function varies along the isoquant. With $\rho>1$, the latter is generally steeper as $K_{n t} / H_{n t}$ increases.

Under these assumptions regarding the technology and assuming free trade and perfect factor mobility within an economic area, an equality between shares arises.

Proposition 1 Given the production function (1), if no barriers to the free movement of goods, physical and human capital exist then

$$
\frac{Y_{n t}}{\sum_{k=1}^{N} Y_{k t}}=\frac{K_{n t}}{\sum_{k=1}^{N} K_{k t}}=\frac{H_{n t}}{\sum_{k=1}^{N} H_{k t}} .
$$


The shares of output, physical and human capital fully equalize for every country $n=$ $1, \ldots, N$. Particularly, each member's share of an area's total output will equal its share of the area's total stock of physical capital and of human capital.

Proof: Marginal products of human capital implied by (1) can be expressed as a function $f$ of human-to-physical capital $(x)$ and as a function $g$ of output-to-physical capital $(y)$. In particular, at any date $t$ :

$$
\frac{\partial Y_{n}}{\partial H_{n}}=f\left(\frac{H_{n}}{K_{n}}\right)=g\left(\frac{Y_{n}}{K_{n}}\right),
$$

where

$$
f(x)=\gamma \delta \rho(x+\rho-1)^{\delta \rho-1}
$$

and

$$
g(y)=\gamma^{\frac{1}{\delta \rho}} \delta \rho y^{1-\frac{1}{\delta \rho}} .
$$

Functions $f$ and $g$ are strictly decreasing. In particular,

$$
\frac{\partial f}{\partial x}=\gamma \delta \rho(\delta \rho-1)(x+\rho-1)^{\delta \rho-2}<0
$$

as the first two terms of the product have opposite signs while the last term is always positive. Namely, $\gamma \delta \rho>0$ and $\delta \rho-1<0$, which follows directly from the domain over which parameters $\gamma, \delta, \rho$ are defined, and

$$
x+\rho-1>\frac{1-\rho}{1-\delta \rho} \delta \rho>0,
$$

which follows from the fact that $x>0$ and $x>\frac{1-\rho}{1-\delta \rho}$. Similarly,

$$
\frac{\partial g}{\partial y}=\gamma^{\frac{1}{\delta \rho}} \delta \rho\left(1-\frac{1}{\delta \rho}\right) y^{-\frac{1}{\delta \rho}}<0
$$

which follows again from the definition of the domain of parameters $\gamma, \delta, \rho$.

Perfect mobility of labour brings about the equalization of value marginal products of human capital across member countries as human capital from the low-return country flows to the high-return country until efficiency wages fully equalize. With free trade the price of the single good are similar across countries. Given this and the strict monotonicity of $f$ and $g$, equality of marginal products implies equality of human-to-physical capital ratios and output-to-capital ratios between any two members of the economic area. Namely, for any pair of countries $j$ and $n$ we obtain the following equality:

$$
\frac{H_{n}}{K_{n}}=\frac{H_{j}}{K_{j}} \text { and } \frac{Y_{n}}{K_{n}}=\frac{Y_{j}}{K_{j}}
$$


which is sufficient to conclude that for any country $n$ within a fully integrated economic area the human capital share coincides with that of physical capital and the physical capital share coincides with that of output. Specifically, employing (3) gives:

$$
\frac{H_{n}}{\sum_{k=1}^{N} H_{k}}=\frac{1}{\sum_{k=1}^{N} \frac{H_{k}}{H_{n}}}=\frac{1}{\sum_{k=1}^{N} \frac{K_{k}}{K_{n}}}=\frac{K_{n}}{\sum_{k=1}^{N} K_{k}}
$$

and

$$
\frac{K_{n}}{\sum_{k=1}^{N} K_{k}}=\frac{1}{\sum_{k=1}^{N} \frac{K_{k}}{K_{n}}}=\frac{1}{\sum_{k=1}^{N} \frac{Y_{k}}{Y_{n}}}=\frac{Y_{n}}{\sum_{k=1}^{N} Y_{k}}
$$

from where the equal-share relationship (2) follows.

This proposition is simply the result of firms' profit maximization, the equalization of value marginal products across countries and the properties of equal ratios. ${ }^{8}$ It has a number of implications. First, though equal-share relationship (2) has been derived in a frictionless environment, a similar expression obtains in the case of, for example, TFP differences across locations and barriers to international labour mobility. While the former are represented in the model by adding country subscript $k$ to $\gamma$, the latter can be captured by a multiplicative wedge $\omega_{k}$. This wedge is a shorthand for all distortions that potentially affect the marginal return to labour: income tax, migration quota, pension system, etc. As both parameters enter expressions for value marginal products directly they impact the allocation of primary factors across countries. Repeating the steps of the proof of Proposition 1, we obtain:

$$
\frac{\alpha_{n} \bar{Y}_{n t}}{\sum_{k=1}^{N} \alpha_{k} \bar{Y}_{k t}}=\frac{\bar{K}_{n t}}{\sum_{k=1}^{N} \bar{K}_{k t}}=\frac{\beta_{n} \bar{H}_{n t}}{\sum_{k=1}^{N} \beta_{k} \bar{H}_{k t}} .
$$

where $\alpha_{k}=\left(\gamma_{k}^{-\delta \rho} \omega_{k}\right)^{-\delta \rho /(1-\delta \rho)}$ and $\beta_{k}=\left(\gamma_{k} \omega_{k}\right)^{-1 /(1-\delta \rho)}$. Importantly "-" represents levels of output and factors that differ from (2). Thus, the introduction of TFP differences and barriers to free mobility though they rescale variables maintain the equal-share relationship. ${ }^{9}$

Second, consider for a moment the relative position of a country within a region by looking at foreign flows of productive factors, mainly human capital, as a contributor to the growth of a selected country. This aspect can be illustrated in our framework by considering immigration, an exogenous inflow $\Delta H>0$ of human capital into the $n$th economic unit that originates from outside the region. ${ }^{10}$ An inflow of human capital from

\footnotetext{
${ }^{8}$ Capital mobility is redundant to establish the result. With the final good being freely traded a single commodity price will prevail among member countries. With labour being the mobile factor of production, we expect it to flow from the low-wage to the high-wage economy until its marginal product is equalized across countries. With similar goods prices and equal wages, the returns to physical capital must equal among countries as long as production technologies are similar.

${ }^{9}$ The last equality of relationship (4) requires, however, one of the following two conditions to hold: either $\rho=1$ or $\alpha_{k}=\alpha_{n}$ in any bilateral comparison of marginal products of human capital.

${ }^{10}$ In contrast, an inflow of migrants from inside the region is endogenous. It responds to cross-country
} 
outside the integrated area (for example, from India) will, at impact, affect relationship (2) for the $n$th country as follows:

$$
\frac{Y_{n t}}{\sum_{k=1}^{N} Y_{k t}}=\frac{K_{n t}}{\sum_{k=1}^{N} K_{k t}}<\frac{H_{n t}+\Delta H}{\sum_{k=1}^{N} H_{k t}+\Delta H}
$$

Thus, migration into country $n$ increases its share of the total stock of human capital. Since the increase in the stock of human capital raises the marginal return to physical capital in country $n$, incentives arise to increase investment in physical capital. Given the increase in both stocks of productive factors, country n's output and share of total area output increase. These adjustments in output and factor stocks continue until the equality of shares in (2) is restored, but now with country $n$ achieving a relatively higher level of economic activity than originally.

Having established the equality of output and factor shares in integrated areas, we now verify its empirical validity. To that end we outline the construction of our data set and then perform empirical tests.

\subsection{Data Sources and Methods}

Let us denote a share of a variable $j \in\{Y, K, H\}$ by $S_{j n t}$. Thus, to compute output shares $S_{Y n t}$ we use:

$$
S_{Y n t}=\frac{Y_{n t}}{\sum_{k=1}^{N} Y_{k t}}
$$

Factor shares $S_{K n t}$ and $S_{H n t}$ are computed analogously. Hence, our sample includes country data on outputs and stocks of physical and human capital. Our data set is a balanced panel of annual data ranging from 1975 till 2009. This time range is particularly chosen because the Arab Spring makes the accuracy of data in key countries like Syria, Egypt and Lybia questionable.

We measure output as gross domestic product (GDP) expressed in international dollars and valued at constant 2000 prices. The main source of data on output is Penn World Tables (PWT) 7.0. We use PWT 5.6, PWT 6.2 and the International Financial Statistics (IFS) database of International Monetary Fund (IMF) as additional data sources where information is unavailable in PWT 7.0. The data on the stock of physical capital till 2004 is obtained from the version 6.2 of PWT. Due to the unavailability of more recent data we use the capital inventory rule on total real investment to extend the series up to year 2009. The data on investment is taken from PWT 6.2 and PWT 7.0. Depreciation rates are estimated using a five-year moving average on depreciation rates implied by the capital inventory rule on available capital stock and investment data. Just as output, investment and physical capital are expressed in international dollars and valued at constant 2000

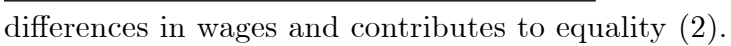


prices. Human capital is measured as total population aged 15 and over that has at least completed secondary education. The data is obtained from Barro and Lee's data set on educational attainment. Because the data is only available on a five-year interval basis and because it exhibits a clear exponential growth we use cubic splines to interpolate missing observations. The data on human capital for Lebanon and Oman is estimated using information on population with secondary and tertiary schooling obtained from their national statistical offices. A more detailed description of the data and the methods employed for interpolation and extrapolation is contained in the Appendix.

For the purpose of our empirical analysis we further compute the shares of output, physical and human capital separately for the countries of the Middle East. Figure 2 illustrates the distribution of all three sets of shares in 2009 where it is clear that Iran takes the highest intra-regional share of all the variables. Likewise, sets of shares are also computed for EU-15 and ALADI and are reproduced in Figures 3 and 4.

Figure 2: Distribution of output and factor shares in MENA.
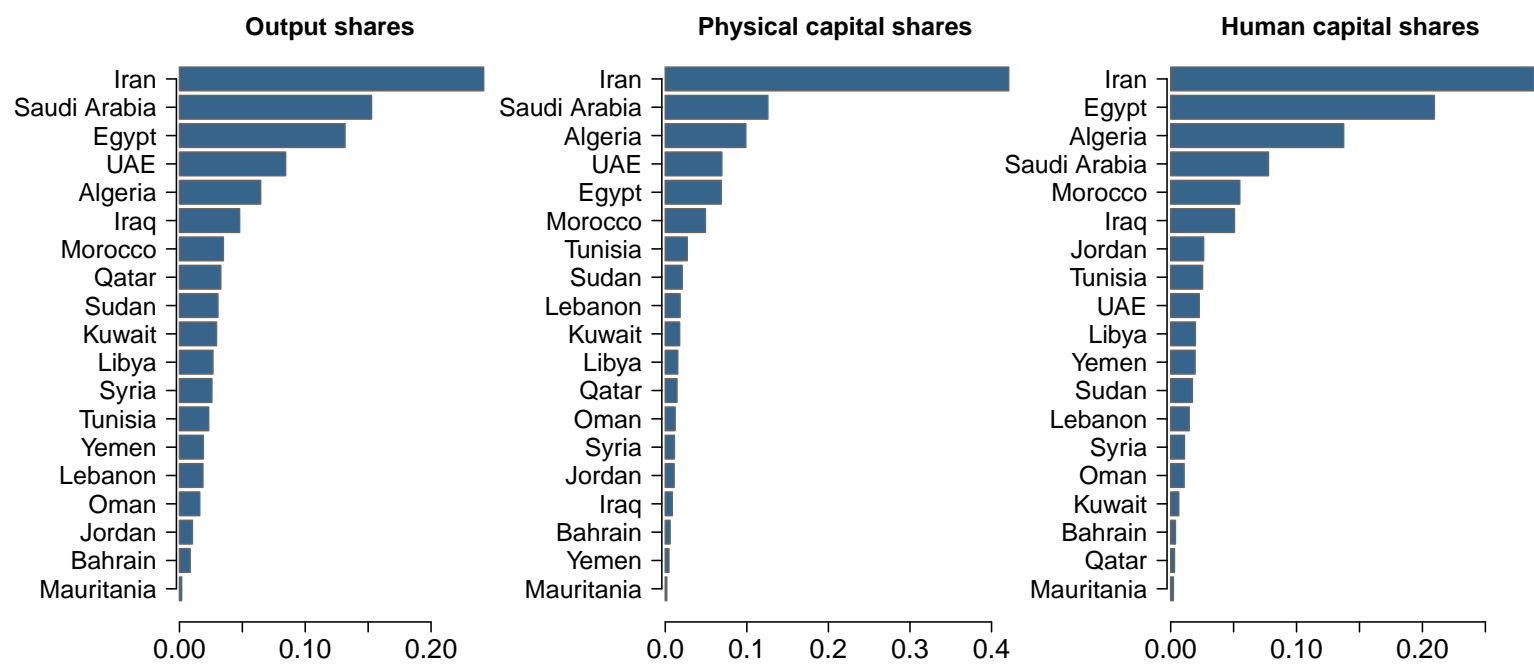

Note: Year 2009.

Source: Own calculations based on Penn World Tables 7.0, 6.2, 5.6, IMF IFS and Barro and Lee (2013).

\subsection{Tests of Proposition 1}

To test whether there is conformity between the ranks of the output and factor shares we compute Spearman rank correlation coefficients at every time point and compare them across regions and over time. Contrary to Pearson correlation, rank correlation not only allows for non linearities to be present in a relationship, but also considerably lowers the influence of large observations that are typical to our data. 
Figure 3: Distribution of output and factor shares in EU-15.

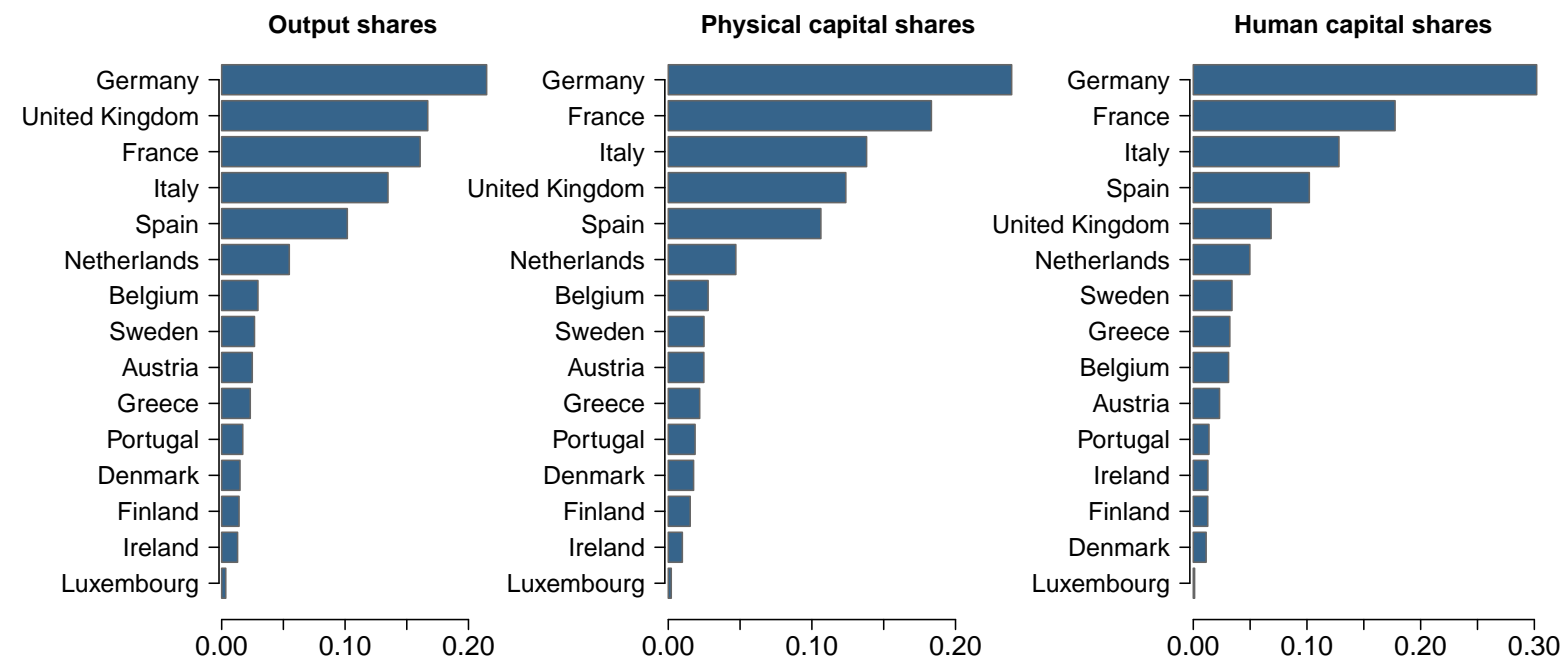

Note: Year 2009.

Source: Own calculations based on Penn World Tables 7.0, 6.2, 5.6 and Barro and Lee (2013).

Figure 4: Distribution of output and factor shares in ALADI.
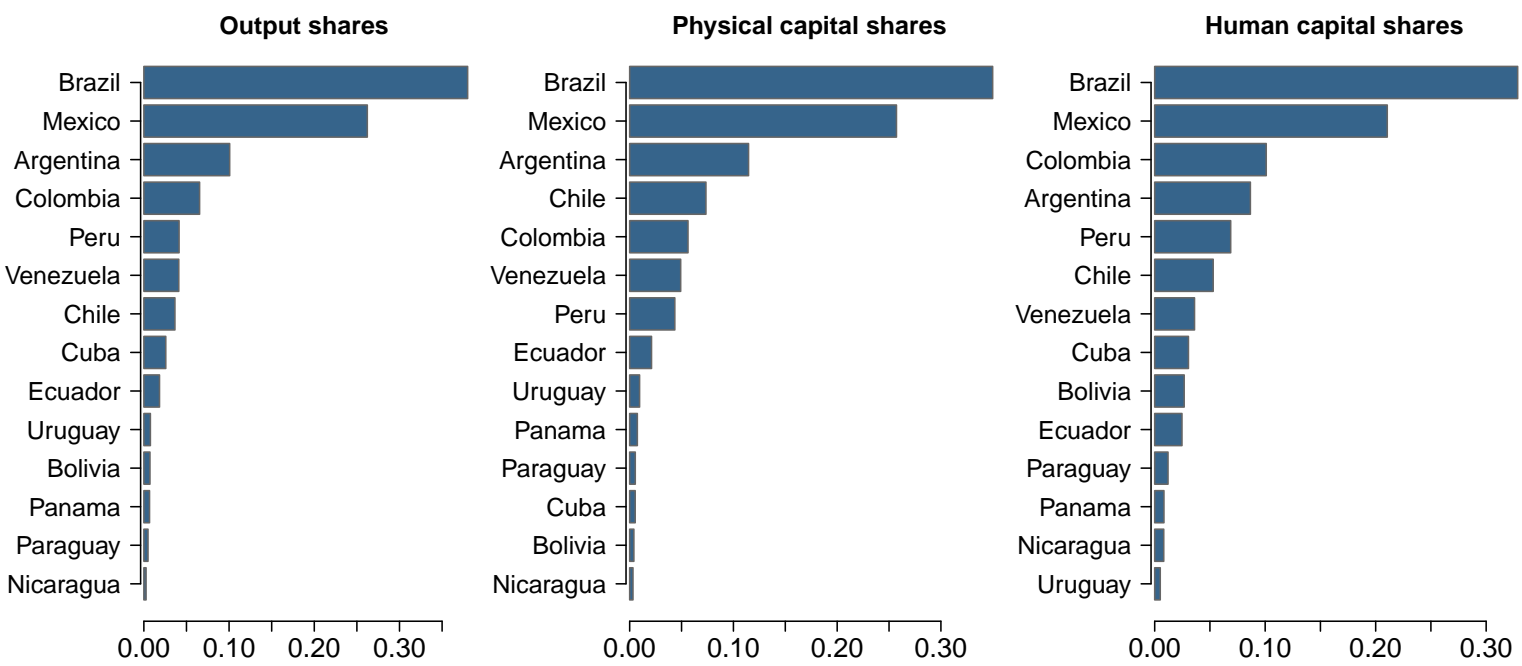

Note: Year 2009.

Source: Own calculations based on Penn World Tables 7.0, 6.2, 5.6 and Barro and Lee (2013).

Table 4 reports pairwise Spearman rank correlations computed for the three regions at different time points. Although reported correlation coefficients are population values and as such are not subject to sampling errors we nevertheless report bootstrap confidence intervals in the brackets to take into account possible data measurement errors. The table reveals a significant positive relationship between any pair of shares. All the coefficients are 
close to or above 0.7 . Thus, a country with a higher ranked output share tends to also have higher ranked factor shares. Particularly high, close to unity, coefficients are observed for EU-15 indicating a nearly perfect rank conformity. Correlations are also relatively stable over time with some but minor over time variation, which means that a country that takes a certain rank position is unlikely to change it quickly.

Table 4: Spearman rank correlations.

\begin{tabular}{|c|c|c|c|}
\hline & $\begin{array}{l}\text { Output-physical } \\
\text { capital }\end{array}$ & $\begin{array}{l}\text { Output-human } \\
\text { capital }\end{array}$ & $\begin{array}{l}\text { Physical capital- } \\
\text { human capital }\end{array}$ \\
\hline \multicolumn{4}{|c|}{ MENA } \\
\hline 1975 & $0.82[0.51,0.95]$ & $0.74[0.42,0.89]$ & $0.85[0.57,0.96]$ \\
\hline 1980 & $0.81[0.47,0.95]$ & $0.75[0.38,0.90]$ & $0.86[0.58,0.97]$ \\
\hline 1985 & $0.86[0.59,0.97]$ & $0.79[0.44,0.94]$ & $0.82[0.45,0.96]$ \\
\hline 1990 & $0.90[0.68,0.97]$ & $0.84[0.56,0.96]$ & $0.82[0.49,0.95]$ \\
\hline 1995 & $0.88[0.63,0.97]$ & $0.80[0.44,0.96]$ & $0.84[0.52,0.95]$ \\
\hline 2000 & $0.86[0.61,0.96]$ & $0.81[0.46,0.96]$ & $0.84[0.54,0.96]$ \\
\hline 2005 & $0.79[0.42,0.96]$ & $0.76[0.40,0.93]$ & $0.76[0.38,0.94]$ \\
\hline 2009 & $0.80[0.45,0.96]$ & $0.71[0.30,0.92]$ & $0.68[0.26,0.91]$ \\
\hline \multicolumn{4}{|c|}{ ALADI } \\
\hline 1975 & $0.93[0.71,1.00]$ & $0.92[0.71,0.98]$ & $0.93[0.69,0.99]$ \\
\hline 1980 & $0.93[0.72,1.00]$ & $0.92[0.63,1.00]$ & $0.89[0.58,1.00]$ \\
\hline 1985 & $0.93[0.71,1.00]$ & $0.94[0.69,1.00]$ & $0.93[0.69,1.00]$ \\
\hline 1990 & $0.95[0.72,1.00]$ & $0.94[0.72,1.00]$ & $0.92[0.66,1.00]$ \\
\hline 1995 & $0.96[0.84,1.00]$ & $0.94[0.76,1.00]$ & $0.87[0.57,0.98]$ \\
\hline 2000 & $0.94[0.75,1.00]$ & $0.93[0.71,1.00]$ & $0.84[0.49,0.97]$ \\
\hline 2005 & $0.92[0.67,1.00]$ & $0.91[0.67,0.99]$ & $0.80[0.39,0.96]$ \\
\hline 2009 & $0.90[0.65,1.00]$ & $0.93[0.70,1.00]$ & $0.82[0.42,0.96]$ \\
\hline \multicolumn{4}{|c|}{ EU-15 } \\
\hline 1975 & $0.97[0.86,1.00]$ & $0.97[0.86,1.00]$ & $0.99[0.90,1.00]$ \\
\hline 1980 & $0.99[0.91,1.00]$ & $0.97[0.86,1.00]$ & $0.98[0.90,1.00]$ \\
\hline 1985 & $0.99[0.94,1.00]$ & $0.99[0.91,1.00]$ & $1.00[0.95,1.00]$ \\
\hline 1990 & $0.99[0.90,1.00]$ & $0.97[0.84,1.00]$ & $0.97[0.86,1.00]$ \\
\hline 1995 & $0.99[0.92,1.00]$ & $0.97[0.84,1.00]$ & $0.98[0.90,1.00]$ \\
\hline 2000 & $1.00[0.95,1.00]$ & $0.98[0.89,1.00]$ & $0.99[0.91,1.00]$ \\
\hline 2005 & $0.99[0.91,1.00]$ & $0.96[0.82,1.00]$ & $0.98[0.89,1.00]$ \\
\hline 2009 & $0.99[0.91,1.00]$ & $0.95[0.80,1.00]$ & $0.96[0.83,1.00]$ \\
\hline
\end{tabular}

Notes: (i) Although correlation coefficients are population values and not subject to sampling errors we report bootstrap confidence intervals in the brackets to account for possible data measurement errors; (ii) $5 \%$ significance level; (iii) Number of bootstrap replications is 5000 .

Though Proposition 1 established the equality of shares, its underlying assumptions can be used to explain why deviations from equality might be observed in empirics. First, part of the equality of shares in (2) breaks down when the parameter space includes $\delta \rho=0$. 
With $\rho=0$ the VES function degenerates to the fixed-coefficient function as a special case: $Y_{n t}=\gamma K_{n t}$. This specification implies redundancy of human capital in the $n$th economy as the employment of human capital is lower than its endowment $H_{n t}$. In this case, the human capital share in (2) no longer equals the other two. Second, in some other economies, human capital might be instead the constraining factor. It is a simple matter to obtain this outcome by interchanging the role of $K_{n t}$ and $H_{n t}$ in (2). In this case, the physical capital share in (2) no longer equals the other two. Lastly, the human capital share in (4) differs from the other two when, as shown in footnote 9 , the assumptions $\rho=1$ or $\alpha_{k}=\alpha_{n}$ are not verified in any bilateral comparison of marginal products of labour.

\section{Steady State Equilibrium Distribution of Shares}

\subsection{Dynamics of Shares}

We assume that changes in shares can be the realization of some particular states of nature. There are numerous reasons why shares could be random. Innovation and discoveries of natural resources are usually believed to follow a random process once investments in those activities have been made. Also, upheavals, military conflicts and natural disasters hit output, stocks of human and physical capital at random. To characterize such randomness we assume that both output and factor shares evolve according to a reflected geometric Brownian motion (RGBM) with a drift parameter $\mu$, volatility $\sigma$, lower bound $b=\min S_{j n t}$ and upper bound $d=\max S_{j n t}$. That is, we assume:

$$
\frac{d S_{j n t}}{S_{j n t}}=\mu d t+\sigma d B_{t}+d L_{t}-d U_{t}
$$

where $B_{t}$ is a Wiener process, while $L_{t}$ and $U_{t}$ denote non-negative, non-decreasing, rightcontinuous processes, guaranteeing reflections every time $S_{j n t}$ goes below the lower or above the upper bound (Harrison, 1985). We further impose a normalization constraint at every time point to ensure share summation to one:

$$
\sum_{n=1}^{N} S_{j n t}=1, \quad t=1, \ldots, T .
$$

The evolution of shares spelled out in (5) recognizes a link between output and primary factors in that the process from which shocks to the shares are derived is common to all. Though the process is similar, the realization of the states of nature might differ across shares. For example, strikes, technical breakdowns and political upheavals disrupt the production of goods with minor impacts on the stocks of production factors. Later in this section, however, we discuss the case of explicitly modelled correlations. Given this we show: 
Proposition 2 If shares evolve according to a reflected Brownian motion given by (5) and its drift and volatility parameters satisfy $\mu<\frac{\sigma^{2}}{2}$, there exists a steady state cumulative distribution of these shares that has the following form:

$$
F_{j n \infty}(S)=P\left(S_{j n \infty} \leq S\right)=1-\frac{S^{\frac{2 \mu}{\sigma^{2}}-1}}{b^{\frac{2 \mu}{\sigma^{2}}-1}-d^{\frac{2 \mu}{\sigma^{2}}-1}}, \quad S \in[b, d] .
$$

Particularly, it is a Pareto distribution with the tail index equalling $\left(1-\frac{2 \mu}{\sigma^{2}}\right) \cdot{ }^{11}$

Proof: Itô lemma applied to $\log S_{j n t}$ yields the following expression for (5) for any initial value $S_{j n 0}$ :

$$
\begin{cases}\log S_{j n t} & =X_{n t}+L_{t}-U_{t} \\ X_{n t} & =\log S_{j n 0}+\left(\mu-\frac{\sigma^{2}}{2}\right) t+\sigma B_{t}\end{cases}
$$

A convenient way to model reflections is to use Skorokhod maps that restrict shares to take values within a given interval. In particular, $L_{t}$ and $U_{t}$ are defined as

$$
\left\{\begin{array}{l}
L_{t}=-\inf _{0 \leq s \leq t}\left(\left\{X_{n s}-\log b\right\} \wedge\{0\}\right) \\
U_{t}=-\inf _{0 \leq s \leq t}\left(\left\{\log d-X_{n s}\right\} \wedge\{0\}\right)
\end{array}\right.
$$

where inf stands for the infimum of a set so that reflections occur now at $\log b$ and $\log d$. For $\mu$ and $\sigma$ such that $\mu<\frac{\sigma^{2}}{2}$ there exists a steady state distribution of (8). Zhang and Du (2010) derive the steady state density function of RGBM with two barriers. The function reads:

$$
f_{j n \infty}(S)=\left(1-\frac{2 \mu}{\sigma^{2}}\right) \frac{S^{\frac{2 \mu}{\sigma^{2}}-2}}{b^{\frac{2 \mu}{\sigma^{2}}-1}-d^{\frac{2 \mu}{\sigma^{2}}-1}} .
$$

The corresponding cumulative distribution is then given by (7)

It is clear from (7) that though realizations of states of nature differ distributions of output and factor shares are similar when $\mu=0$.

An important extension of the proposition is that the steady state distribution remains Pareto even when shares of country $i$ and country $j$ and/or output and factor shares are correlated. The shares must follow a certain pattern of correlations described by the so called skew symmetry condition: $\mathbf{R} \operatorname{diag} \boldsymbol{\Sigma}+\operatorname{diag} \boldsymbol{\Sigma} \mathbf{R}^{\boldsymbol{T}}=2 \boldsymbol{\Sigma}$, where $\boldsymbol{\Sigma}$ is a correlation matrix, $\operatorname{diag} \boldsymbol{\Sigma}$ is a diagonal matrix whose entries are the variances of each single component of a multivariate RGBM and $\mathbf{R}$ is a reflection matrix that corrects correlations when one of the single components hits the barrier (see Harrison and Williams, 1987; Dai and Harrison, 1992).

\footnotetext{
${ }^{11}$ Note that the tail index can take any positive value. The adding-up constraint (6) that we impose further will prevent shares from being infinite in expectation in case of tail index smaller than 1.
} 
Given Proposition 2 we are able to focus on the steady state analysis of shares $S_{n j}$ and therefore omit the time index $t$. We rank shares in a descending order attributing the highest rank to the country having the largest share of variable of interest within the area. Then a country ranked the $n$th has the $n$th largest share within the area or, equivalently, $n$ countries have their shares larger or equal to the $n$th largest share. This allows to deduce the following relationship between the cumulative distribution function and a rank:

$$
P\left(S_{j k} \geq S_{j n}\right)=\frac{R_{j n}}{N}
$$

Using the cumulative distribution function of shares (7) we obtain:

$$
P\left(S_{j k} \geq S_{j n}\right)=1-P\left(S_{j k}<S_{j n}\right)=\frac{S_{j n}^{-\beta}}{b^{-\beta}-d^{-\beta}}
$$

where $\beta=1-\frac{2 \mu}{\sigma^{2}}$. Using expressions (4.1) and (9) we obtain a non-linear relationship between a rank and a share:

$$
S_{j n}=\frac{\lambda^{1 / \beta}}{R_{j n}^{1 / \beta}},
$$

where $\lambda=\frac{N}{b^{-\beta}-d^{-\beta}}$.

\subsection{Empirical Results}

Having described the properties of our fully integrated group of economies through Propositions 1 to 2 we now estimate the long-term relationship derived from the steady state distribution of shares and show ways to apply Maximum Likelihood on available data to estimate $\mu$ and $\sigma$.

\subsubsection{Power Law}

Equation (10) is a long-run relationship derived from the steady state distribution of shares, a so called power law. The distribution of ranks $S_{j n}$ is said to follow a power law when, for sufficiently large values of the $n$-th ranked variable $S_{j n}$, its size is inversely proportional to a power of its rank. Taking the natural logarithm of (10) yields:

$$
\log R_{j n}=\log \lambda-\beta \log S_{j n}, \quad j \in\{Y, K, H\} .
$$

To test whether the power law holds in our sample and whether the exponent of the power law is close to unity we run simple OLS regressions on a cross-section at every time point using the $\log$ specification above. To correct for a possible small sample bias we 
follow Gabaix and Ibragimov (2011) and use adjusted ranks:

$$
\log \left(R_{j n}-1 / 2\right)=\log \lambda-\beta \log S_{j n}, \quad j \in\{Y, K, H\} .
$$

Figure 5 shows the estimated slopes of regression (11) for the three sets of shares in the three regions under consideration.

Figure 5: Estimated power law exponents $-\beta$.
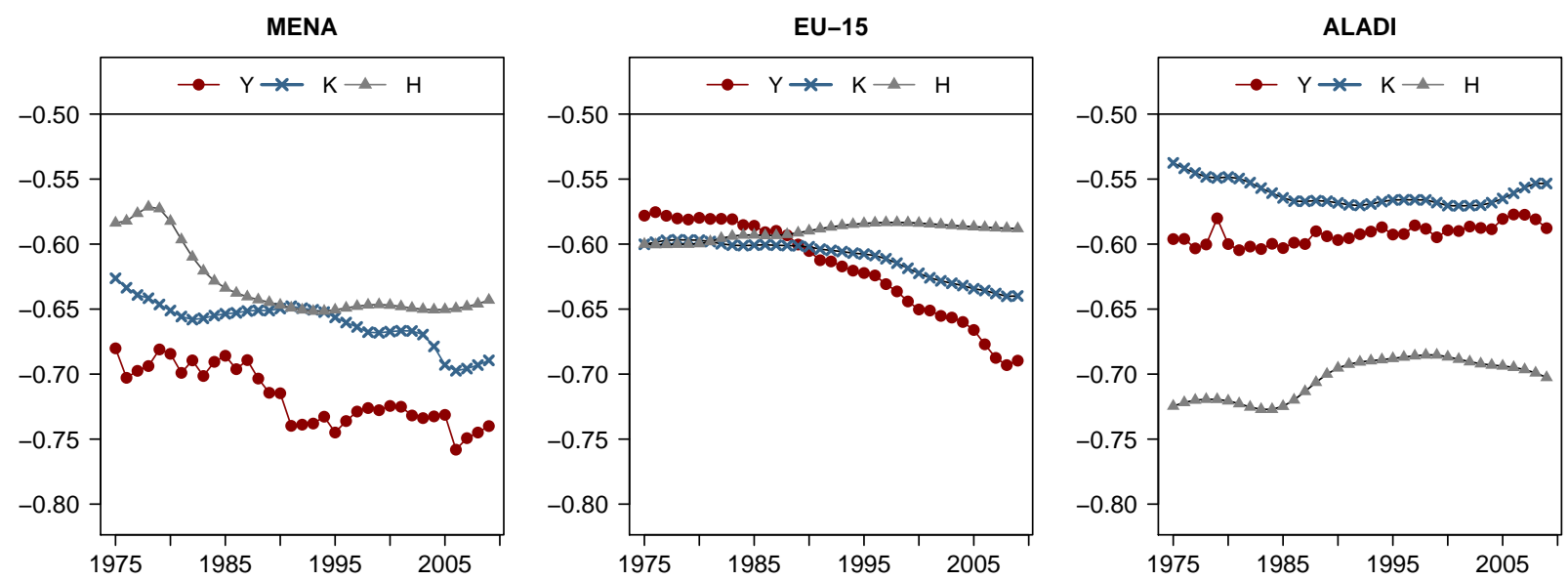

Notes: (i) The exponents are significantly different from zero and one at the $5 \%$ level. (ii) The coefficient of determination varies between 0.60 and 0.91 .

Estimated exponents are all significantly different from zero at the $5 \%$ significance level. The data therefore can be indeed well described by power laws. The estimates, however, are all significantly different from one, which indicates that there are significant deviations of the share distributions from Zipf's law. A slight decreasing trend, however, can be observed for most of the exponents, which is a sign that, although slowly, convergence to Zipf's law may be taking place.

\subsubsection{Maximum Likelihood Estimation of RGBM Parameters}

The second part of our empirical analysis uses historical series to estimate the parameters of the reflected geometric Brownian motion. We follow the estimation approach outlined in Aït-Sahalia (2002) and apply Maximum Likelihood (ML) on available data for output and factor shares to estimate the parameters $\mu$ and $\sigma$.

Let $\theta=(\mu, \sigma)^{\prime}$ denote a vector of RGBM parameters. A critical step is the derivation of the conditional density function of normalized RGBM. No such density in its analytical form exists in the literature. To obtain approximate estimates we use the density of RGBM with a sole lower barrier derived in Veestraeten (2008). In this case the density reads: 


$$
\begin{aligned}
P\left(S_{j n t} \mid S_{j n, t-\Delta} ; \theta\right) & =\frac{1}{\sigma S_{j n t} \sqrt{2 \pi \Delta}} \exp \left[-\frac{\left(\ln S_{j n t}-\ln S_{j n, t-\Delta}-\gamma_{1} \Delta\right)^{2}}{2 \sigma^{2} \Delta}\right] \\
& +\frac{1}{\sigma S_{j n t} \sqrt{2 \pi \Delta}} \exp \left[\gamma_{2}\left(\ln b-\ln S_{j n, t-\Delta}\right)\right] \exp \left[-\frac{\left(\ln S_{j n t}+\ln S_{j n, t-\Delta}-2 \ln b-\gamma_{1} \Delta\right)^{2}}{2 \sigma^{2} \Delta}\right] \\
& -\gamma_{2} \frac{1}{S_{j n t}} \exp \left[\gamma_{2}\left(\ln S_{j n t}-\ln b\right)\right]\left(1-\Phi\left[\frac{\ln S_{j n t}+\ln S_{j n, t-\Delta}-2 \ln b+\gamma_{1} \Delta}{\sigma \sqrt{\Delta}}\right]\right),
\end{aligned}
$$

where

$$
\begin{aligned}
& \gamma_{1}=\mu-\frac{\sigma^{2}}{2} \\
& \gamma_{2}=\frac{2}{\sigma^{2}} \gamma_{1} .
\end{aligned}
$$

$S_{\text {jnt }}$ denotes as before country's $n$ share of variable $j$ at time point $t$ and $\Delta$ is a time step equalling 1 for annual data. ML therefore solves:

$$
\hat{\theta}=\underset{\theta}{\arg \max } \ell(\theta)
$$

with the $\log$-likelihood function $\ell$ being:

$$
\ell(\theta)=\sum_{t=\Delta}^{T} \sum_{n=1}^{N} \ln \left[P\left(S_{j n t} \mid S_{j n, t-\Delta} ; \theta\right)\right] .
$$

Solution to (12) can be obtained by various numerical optimization algorithms such as, for example, the algorithm of Broyden-Fletcher-Goldfarb-Shanno (BFGS).

Estimation results of model parameters $\mu$ and $\sigma$ for each set of shares are presented in Table $5 .{ }^{12}$ From the table it is clear that the volatility of output shares is the largest. This is partly due to the fact that output is a flow variable and is therefore more volatile than the more steady stocks of physical and human capital. In addition, output volatility in the Middle East is high though expected since MENA countries have experienced numerous armed conflicts that significantly affected its output. That volatility in EU is so low can be explained by policy coordination that is a key to the region. For example, consider the scenario where all $N$ countries in the integrated area put in place a coordinated policy such that the human capital of each member country increases by a factor $\lambda(\lambda>1)$. Then, using (2):

$$
\frac{Y_{n t}}{\sum_{k=1}^{N} Y_{k t}}=\frac{K_{n t}}{\sum_{k=1}^{N} K_{k t}}=\frac{\lambda H_{n t}}{\sum_{k=1}^{N} \lambda H_{k t}}=\frac{H_{n t}}{\sum_{k=1}^{N} H_{k t}} .
$$

In this situation shares are not modified and the relative position of each country in the

\footnotetext{
${ }^{12}$ We tested this estimation procedure on numerous simulated RGBMs with different $\mu$ and $\sigma$ to see how estimation using normalized data affects parameter estimates. The method delivers estimates that are consistent with true parameter values when simulated data is non-normalized. When simulated RGBM data is normalized and then used as input for estimation, the method still delivers volatility (but not drift) estimate close to its true value.
} 
Table 5: Estimates of drift and volatility parameters.

\begin{tabular}{cccccc}
\hline \hline & & \multicolumn{2}{c}{ Full sample $(1975-2009)$} & \multicolumn{2}{c}{$1982-2009$} \\
\hline \hline Region & Variable & Drift $\mu$ & Volatility $\sigma$ & Drift $\mu$ & Volatility $\sigma$ \\
\hline \hline \multirow{2}{*}{ MENA } & Output shares $S_{Y}$ & $0.013^{*}$ & $0.117^{*}$ & 0.006 & $0.106^{*}$ \\
& Physical capital shares $S_{K}$ & $0.005^{*}$ & $0.041^{*}$ & $0.003^{*}$ & $0.028^{*}$ \\
& Human capital shares $S_{H}$ & 0.002 & $0.037^{*}$ & 0.001 & $0.030^{*}$ \\
\hline \multirow{2}{*}{ EU-15 } & Output shares $S_{Y}$ & $0.004^{*}$ & $0.020^{*}$ & $0.003^{*}$ & $0.020^{*}$ \\
& Physical capital shares $S_{K}$ & $0.003^{*}$ & $0.012^{*}$ & $0.002^{*}$ & $0.012^{*}$ \\
& Human capital shares $S_{H}$ & $-0.007^{*}$ & $0.023^{*}$ & $-0.009^{*}$ & $0.022^{*}$ \\
\hline \multirow{2}{*}{ ALADI } & Output shares $S_{Y}$ & $0.001^{*}$ & $0.053^{*}$ & 0.000 & $0.057^{*}$ \\
& Physical capital shares $S_{K}$ & 0.000 & $0.024^{*}$ & 0.001 & $0.021^{*}$ \\
& Human capital shares $S_{H}$ & $-0.004^{*}$ & $0.024^{*}$ & $-0.006^{*}$ & $0.023^{*}$ \\
\hline \hline
\end{tabular}

Note: $*$ denotes statistical significance at the $5 \%$ level.

total remains unchanged. It is clear from the above equation that complete harmonization of policies, expressed in growth factors, makes these shares deterministic and does not modify the distribution of shares of member countries. Hence, if one abstracts from random shocks then the volatility of shares would be zero according to this result. This is a useful benchmark for our empirical analysis.

\section{Assessing the Degree of Economic Integration}

\subsection{Theoretical Shares}

Assume further without loss of generality that country 1 has the largest and country $N$ has the smallest share of variable $j$ in the area. That is, assume the following:

$$
S_{j 1} \geq S_{j 2} \geq \ldots \geq S_{j N}, j \in\{Y, K, H\}
$$

Given the above information, we derive the shares that describe the steady state equilibrium of an integrated area:

Proposition 3 The steady state distribution of shares is uniquely determined by the drift parameter $\mu$, volatility $\sigma$ and the number of countries $N$. Particularly, shares are the solution to the following set of equations

$$
\frac{S_{j 1}}{S_{j 2}}=2^{\frac{1}{\beta}}, \frac{S_{j 1}}{S_{j 3}}=3^{\frac{1}{\beta}}, \ldots, \frac{S_{j 1}}{S_{j N}}=N^{\frac{1}{\beta}} .
$$

and

$$
S_{j 1}=\frac{1}{\sum_{n=1}^{N} n^{-\frac{1}{\beta}}}
$$


Proof. Using (10) and taking the ratio of the first share over the second share, the first share over the third, etc. gives the sequence of ratios in the proposition. The definition of shares implies also that the same rule holds not only for the shares, but also for the levels of the variables $j \in\{Y, K, H\}$ :

$$
\frac{j_{1}}{j_{2}}=2^{\frac{1}{\beta}}, \frac{j_{1}}{j_{3}}=3^{\frac{1}{\beta}}, \ldots, \frac{j_{1}}{j_{N}}=N^{\frac{1}{\beta}} .
$$

This in turn together with the definition of shares uniquely determines the share of the first ranked country or the largest share as a function of the number of countries only. Namely:

$$
S_{j 1}=\frac{j_{1}}{\sum_{n=1}^{N} j_{n}}=\frac{1}{\sum_{n=1}^{N} \frac{j_{n}}{j_{1}}}=\frac{1}{\sum_{n=1}^{N} n^{-\frac{1}{\beta}}} .
$$

Shares of remaining countries can be uniquely determined using (13).

Proposition 3 gives rise to a number of observations. First, assuming $\mu=0^{13}$ implies $\beta=1$ and Zipf's law: the share of the first ranked country is twice as large as the share of the second ranked country, three times as large as the share of the third country and so on. Also, more importantly, Proposition 3 enables a direct computation of shares for any region under investigation. ${ }^{14}$ Table 6 applies the proposition to the Middle East and gives the complete distribution of shares for the region. Likewise Table 6 includes the theoretical distribution of shares for our two control groups, namely the EU-15 $(N=15)$ and the Latin American Integration Association $(N=14)$. It is worth noting that as long as the drift parameter $\mu$ is zero the steady state distribution is not affected by volatility. This allows for heterogeneity of volatility parameters across variables and across countries. We denote the steady state distribution as $\bar{S}$.

\footnotetext{
${ }^{13} \mu=0$ follows from the adding-up constraint (6). Let $g_{j n t}=\frac{S_{j n t}}{S_{j n, t-1}}-1$ denote the growth rate of factor $j$, country $n$ at time point $t$. Then (6) implies $\sum_{n=1}^{N} S_{j n, t-1} g_{j n t}=0$. Taking average of this expression over time gives $E_{t} \sum_{n=1}^{N} S_{j n, t-1} g_{j n t}=\sum_{n=1}^{N} S_{j n, t-1} E_{t} g_{j n t}=0$ and because in our model the drift parameter $\mu$ does not vary across countries, this holds only if $E_{t} g_{j n t}=0$. Therefore, the average growth rate must be zero.

${ }^{14} \mathrm{An}$ implicit property of the concept of shares is share summation to one given by (6). This constraint in combination with the result of Proposition 3 can be used to express the barriers of the RGBM in terms of its drift and volatility parameters. This is useful in identifying the model parameters when estimating the model and running numerical simulations. To that end, we use the expression of the first share as implied by (10) and set it equal to the first share found in (14) to obtain a non linear relationship between the upper and the lower barrier of RGBM. The upper barrier is then $d=\left\{b^{-\beta}-\frac{N}{\left(\sum_{n=1}^{N} n^{-\frac{1}{\beta}}\right)^{-\beta}}\right\}^{-\frac{1}{\beta}}$ and is uniquely determined by drift, volatility, the number of countries and the lower barrier of the process. Because model parameters are time invariant this expression holds also outside of the steady state and it can be used as an additional constraint when estimating the parameters of the model. When the upper barrier is infinite, the lower barrier can be determined by $b=\frac{N^{-\frac{1}{\beta}}}{\sum_{n=1}^{N} n^{-\frac{1}{\beta}}}$.
} 
Table 6: Steady state distribution of shares $(\mu=0)$.

\begin{tabular}{|c|c|c|}
\hline Region & $\begin{array}{l}\text { Number of } \\
\text { countries }\end{array}$ & $\begin{array}{l}\text { Theoretical shares } \\
\text { (descending) }\end{array}$ \\
\hline Middle East & 19 & $\begin{array}{lllllllll}0.282 & 0.141 & 0.094 & 0.070 & 0.056 & 0.047 & 0.040 & 0.035 & 0.031 \\
0.028 & 0.026 & 0.023 & 0.022 & 0.020 & 0.019 & 0.018 & 0.017 & 0.016 \\
0.015 & & & & & & & & \\
\end{array}$ \\
\hline $\begin{array}{l}\text { Latin American Integration } \\
\text { Association }\end{array}$ & 14 & 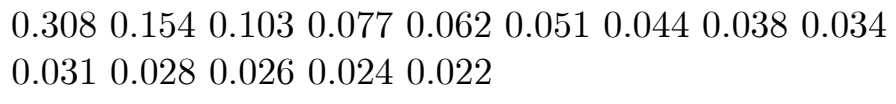 \\
\hline EU-15 & 15 & 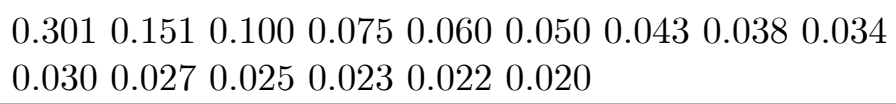 \\
\hline
\end{tabular}

\subsection{Measurement of Integration}

Given the theory and the empirical analysis of the preceding sections we now assess and interpret the gap between the limiting distribution of Table 6 and the observed outcomes characterized by the data.

We measure the degree of economic integration by an integration index $I_{E}\left(\bar{S}, S_{t}\right)$ which is a transformed Euclidean distance. It is defined as

$$
I_{E}\left(\bar{S}, S_{t}\right)=e^{-E\left(\bar{S}, S_{t}\right)}
$$

where $E\left(\bar{S}, S_{t}\right)$ is the Euclidean distance, measuring the deviation of observed shares $S_{j n t}$ from their theoretical counterparts $\bar{S}_{j n}$ found by applying Proposition 3:

$$
E\left(\bar{S}, S_{t}\right)=\frac{1}{3} \sum_{j=Y, K, H} \sqrt{\sum_{n=1}^{N}\left(\bar{S}_{j n}-S_{j n t}\right)^{2}} .
$$

The Euclidean metric is always non-negative and takes the value zero when for each variable $j$ and for each $n$ ranked country, $S_{j n t}=\bar{S}_{j n}$ : this is the property that arises under full integration. The lower is the degree of economic integration the greater is the deviation of the measure from zero, the lower is the value of $I_{E}\left(\bar{S}, S_{t}\right) .{ }^{15}$ Due to share summation to one in (6) there exists a strictly positive lower bound of the measure. We estimate this value to be equal to 0.55 . This estimate is the minimum value of (15) obtained by taking 10000 bootstrap samples with replications from the data on an extended set regions. ${ }^{16}$

\footnotetext{
${ }^{15}$ To test robustness of our findings to different measures of distance between observed and theoretical shares we also compute the Theil entropy index. The index is given by $T\left(\bar{S}, S_{t}\right)=$ $\frac{1}{3} \sum_{j=Y, K, H}\left(\sum_{n=1}^{N} \bar{S}_{j n} \ln \left(\frac{\bar{S}_{j n}}{S_{j n t}}\right)\right)$ and respectively the integration measure $I_{T}\left(\bar{S}, S_{t}\right)=e^{-T\left(\bar{S}, S_{t}\right)}$. Like Euclidean integration index the Theil index takes the maximum value of unity when observed shares coincide with their theoretical counterparts and there exists a positive minimum value due to share summation to one. The results using this index lead to the same conclusions as the results of integration index $I_{E}$.

${ }^{16}$ The regions we considered were the Middle East, the Pan-Arab Arab Free Trade Area, Latin American Integration Association, EU-15, Gulf Cooperation Council, Mercosur, Andean Community and EU-12
} 
The integration index therefore takes values within the $(0.55,1]$ interval, with 1 arising under full integration. ${ }^{17}$

Computation of $I_{E}\left(\bar{S}, S_{t}\right)$ makes use of the following information. Theoretical shares are found in Table 6 while observed shares are ranked in the descending order so that rank $1(n=1)$ is attributed to the country with the largest share in the area; rank $2(n=2)$ to the second largest share; etc. Figure 6 displays the computed index values.

Figure 6: Integration measure $I_{E}$.

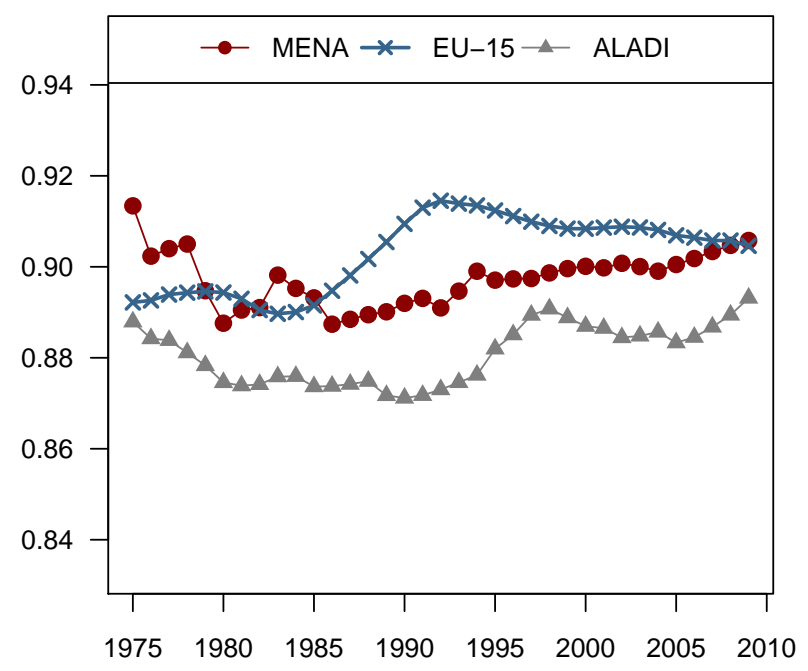

The results suggest that since mid 1980s the degree of economic integration is the highest in the EU-15. However, MENA and ALADI also show high and increasing index values. ${ }^{18}$ Surprisingly, the value of the index in the Middle East is comparable to the EU15 in 2009, at the height of the financial crisis and just before the Arab Spring. The values of the indices are, however, all significantly lower than unity suggesting that although high, integration in MENA and EU-15 is incomplete (see Figure 7). ${ }^{19}$

(EU-15 excluding non euro countries).

${ }^{17}$ Our results are also robust with respect to the transformation we choose to apply to Euclidean distance. In particular, applying the linear transformation $I_{T}\left(\bar{S}, S_{t}\right)=1-E\left(\bar{S}, S_{t}\right)$ does not change the results. This is due to highly concentrated values that the Euclidean measure takes. Given those values both linear and exponential transformations produce almost identical results.

${ }^{18}$ Slope estimate of the integration index regression on time is significant at the $5 \%$ level for the period $1980-2009$

${ }^{19}$ We note, however, that our data is non sampled so that the sampling error is zero and our computed integration index is a true population value for which no confidence intervals exist. Statistical significance in this case accounts rather for possible data measurement errors. 
Figure 7: Integration measure $I_{E}$ with estimated confidence bounds.
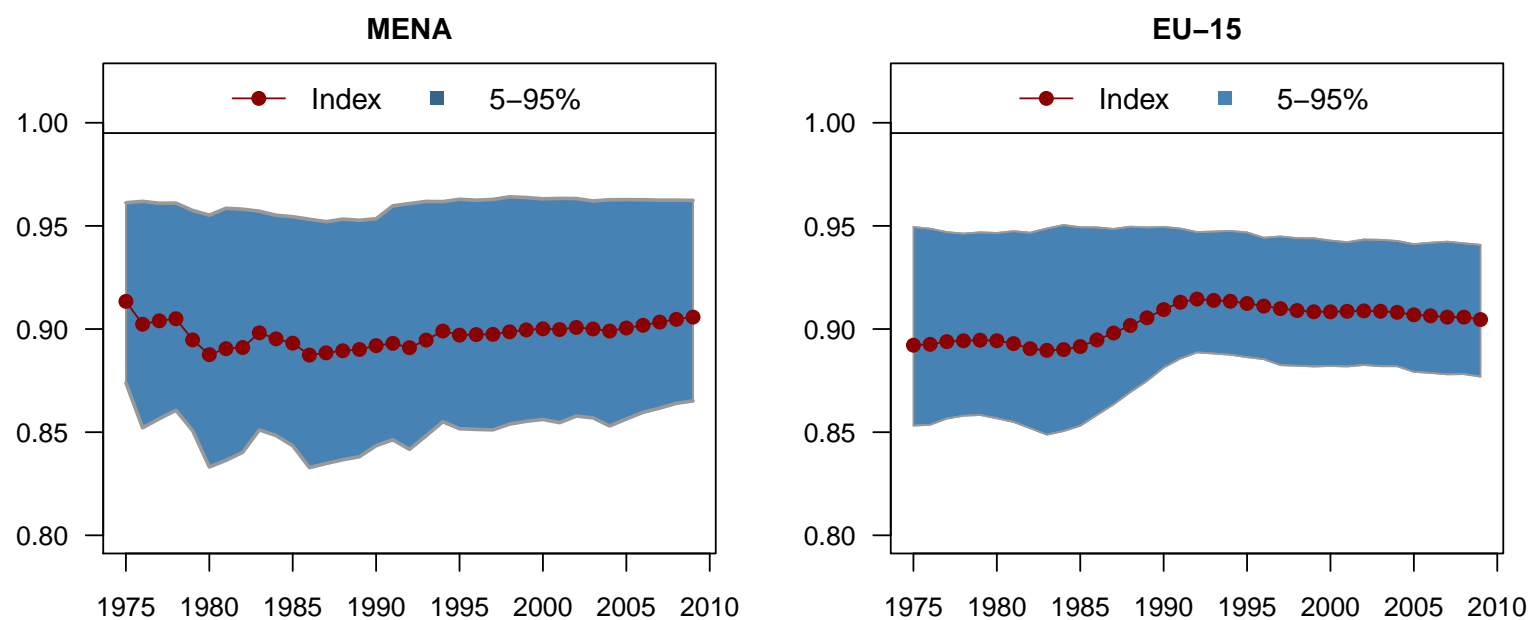

Note: Shaded area denotes a 95\% confidence interval obtained by taking 10000 bootstrap samples with replications.

\subsection{Regional Comparisons}

The computation of the integration index also reveals considerable regional differences. For example, the results indicate that the degree of integration in MENA is lower than that in the countries that constitute PAFTA (also known as the Greater Arab Free Trade Area or GAFTA). PAFTA has a long history in trying to promote trade and economic cooperation between its members with first initiatives taken as early as 1950s. While most of the earlier agreements were poorly implemented and hardly effective, Figure 8 may suggest that creation of PAFTA did have a positive effect. ${ }^{20}$ Another economic area in the Middle East - GCC - shows instead a lower integration level. It may be explained by the fact that most of the GCC economies are major world oil exporters and as such direct most of its trade to non-GCC countries. Moreover, Saudi Arabia being the only large GCC state, clearly dominates the total output of the region as well as its physical and human capital. Because its gains from intra-regional trade are unlikely to be large so would be the gains of the entire region suggesting that there indeed exists a limit to the degree of integration in the regions that consist of one large and a few smaller economies. The index takes even lower values for the Southern Common Market (Mercosur). ${ }^{21}$ Just like GCC Mercosur also includes a clear dominant member - Brazil - that takes the largest

\footnotetext{
${ }^{20}$ Péridy and Abedini (2008), for example, find a $20 \%$ increase in intra-regional trade since the implementation of the agreement.

${ }^{21}$ Mercosur is a customs union that currently comprises Argentina, Brazil, Paraguay, Uruguay and Venezuela. The agreement is in force since 1988 as notified to WTO.
} 
share in regional output, physical and human capital. Andean Community (Andean), ${ }^{22}$ another economic area in the South American continent, shows instead an integration level comparable to that of MENA. These results are in line with other empirical studies on the effectiveness of trade agreements in Latin America. ${ }^{23}$

Figure 8: Integration measure in different regions of the Middle East and Latin America.

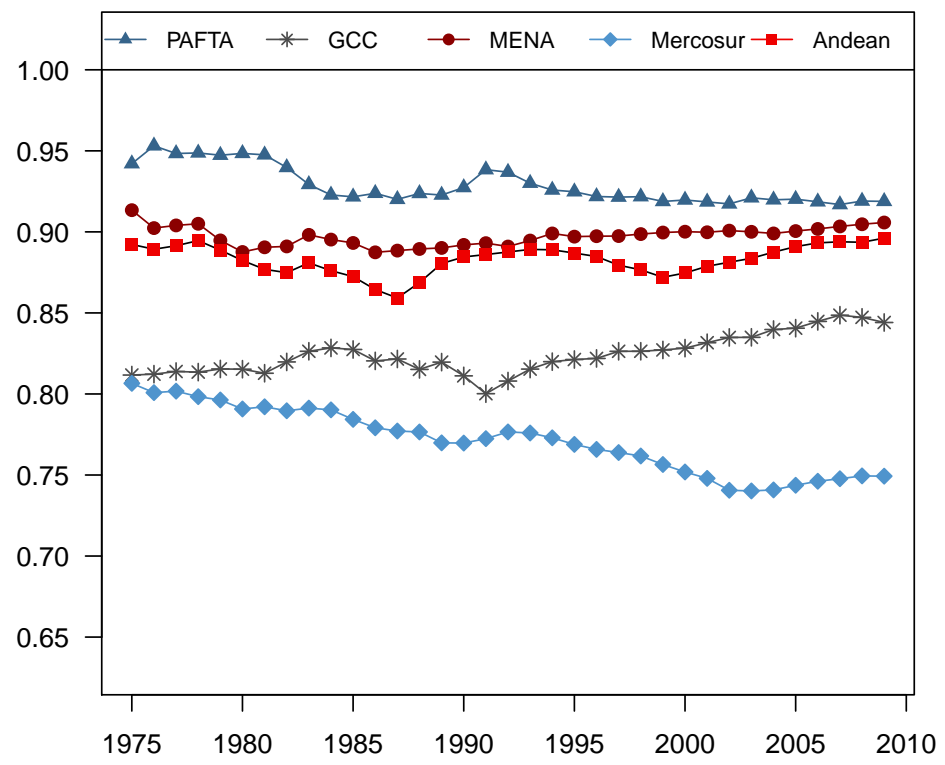

\subsection{Re-computed Integration Measures}

Our results so far indicate that economic integration in the Middle East is seemingly comparable to that of EU-15 in 2009. Is it due to economic factors or to any distortion in our measurement? These questions raise the issue of robustness of our results. To that end we use the results on the conformity of ranks implied by Proposition 1 and then re-compute our indices.

Spearman rank correlations in Section 3.3 indicate that the conformity of ranks is not perfect, i.e. the equal-share relationship, that should hold in our fully integrated benchmark, does not always hold in the data. We did not take this into account while computing the deviations from the fully integrated benchmark in our index (16). We essentially missed to assure that the country that ranks the $n$th in the observed distribution of shares is the same across all types of shares. There are three ways to re-compute index

\footnotetext{
${ }^{22}$ Andean Community is a customs union that consists of Bolivia, Colombia, Ecuador and Peru. The union took effect in 1991 for trade in goods and was extended in 2005 to include trade in services.

${ }^{23}$ For example, in their gravity analysis of bilateral trade flows between Mercosur countries García et al. (2013) find positive but very moderate effects of the agreement on intra-Mercosur trade. In a similar framework Carrillo-Tudela and A Li (2004) investigate the impact of both Mercosur and Andean agreements on intra-regional trade in several product classifications and find positive effects in only a very few product classifications with more significant results for Andean than for Mercosur.
} 
(16) so that this distortion was accounted for and the deviations from the fully integrated benchmark were quantified more accurately. We can compute the index based on the observed ranking of countries at a given year by: (i) output shares; (ii) physical capital shares; (iii) human capital shares. For example, let us focus on the latter and consider the case of the Iranian Revolution in 1979.

A glance at the data reveals that the Iranian Revolution caused a severe decline in the output share of Iran. The share dropped to $17.6 \%$ in 1980 making Iran the second ranked country after Saudi Arabia. The Iran-Iraq war furthered the decline. Nevertheless, Iran still ranked the first in its factor shares with the physical capital share equalling $44.6 \%$ and the human capital share equalling $29.8 \%$. The equal-share relationship is clearly violated in this case and penalties for such violations must be introduced in (16) to accurately quantify deviations from the fully integrated benchmark. Thus, Iran is ranked the first in 1980 for both human $(H)$ and physical capital $(K)$. To preserve the equality of shares, Iranian output $(Y)$ is positioned the first though it is not, which introduces a large gap between $\bar{S}_{1}$ and $S_{Y 1,1980} . E\left(\bar{S}, S_{t}\right)$ increases and the integration measure decreases as a result of this correction. The more a country violates the equal share relationship the larger are the deviations and the smaller is the value of the integration index. Likewise the revision of the integration index can be performed using observed output and physical capital shares instead.

Figure 9: Integration measure re-computed.

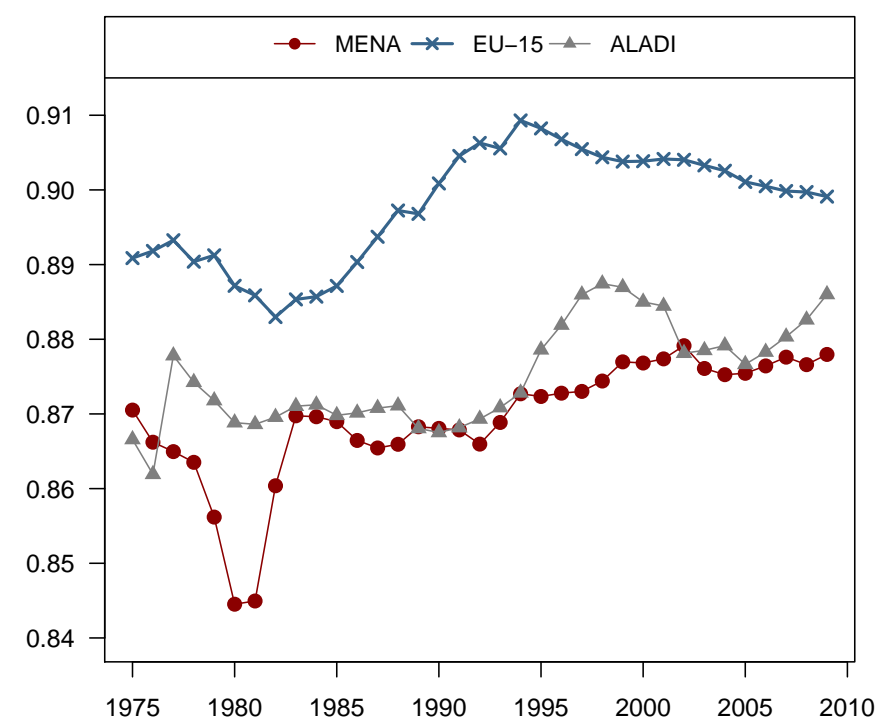

Note: The computation of the integration measure is performed attributing the $n$th largest theoretical share to the country with the $n$th largest human capital share at a given year. The results are similar when computation is performed based on physical capital and output shares.

Figure 9 illustrates the re-computed integration index. Output and physical capital 
based computations yield analogous results. ${ }^{24}$ As Figure 9 suggests, when equality of shares is taken into account, the integration index takes higher values for EU-15 throughout the entire time period analyzed including also 2009 and the the period preceding 1980s. This is because conformity of ranks is higher in EU-15 and therefore the equal-share relationship is met closer. Nevertheless, the corrected index value for MENA in 2009 is only 2.35 percent lower than that of EU-15 implying that the extent of integration in the Middle East is effectively larger than commonly believed.

\section{Counterfactuals}

The analysis in Klein and Ventura (2009) leads us to conclude that regulation of labour mobility is a distortion of first-order importance. They quantify that even small differences in barriers to labour mobility can have substantial implications for the allocation of labour forces as well as the size of output and capital stocks. In Bernanke (2005), Gourinchas and Rey (2014), a powerful case is made that demographic characteristics can also explain global imbalances. This section explores the quantitative implications of our results.

A country's stock of human capital in our empirical analysis is measured by multiplying the percentage of its population aged 15 and over with at least a secondary level of education times its local population. This construct includes thus a policy variable, the rate of educational attainment, and a demographic variable, population. Policy makers can affect the former by closing gender gaps in education and changing the ending age of compulsory schooling; they can alter the latter by removing barriers to international labour mobility.

Focusing on the Middle East in year 2010, we compute the distribution of human capital that would prevail under complete integration. Specifically, given the actual distribution of human capital in 2010, our numerical exercise solves for the 19 unknown stocks of human capital such that it matches the MENA theoretical shares of Table 6. Our numerical results are reproduced in column (2) of Table 7 and are compared to actual stocks in column (3).

Results of Table 7 suggest that for a large number of countries in the Middle East a significant increase in human capital is needed to achieve the level compatible with full integration: the percentage change in column (3) is positive for the majority of coun-

\footnotetext{
${ }^{24}$ The output based computation suggests an abrupt drop in the the degree of integration in EU-15 after 2001. A look at the data reveals that an abrupt decline in the measure occurs because the two large EU-15 economies, UK and France, interchange their positions in output share ranking. The output share of UK increased from $16.00 \%$ in 2000 to $16.06 \%$ in 2001 and turned out to be higher than $16.05 \%$, the 2001 output share of France. This must have had a significant impact on the index as now the observed UK shares were compared to the second largest theoretical share. Particularly large deviations would become for observed human capital shares, in which the UK appears to be the fifth ranked country (see also Figure 3). Further inspection of the human capital data in Barro and Lee (2013) reveals that the number of adults with at least completed secondary education is unusually low in the UK (see the Appendix). Because of possible data inaccuracy we do not interpret this drop as an actual drop in the extent of integration and conclude that the degree of integration has been persistently higher in EU-15.
} 
Table 7: Counterfactual implications: complete integration.

\begin{tabular}{lrrr}
\hline \hline \multirow{2}{*}{ Country } & \multicolumn{2}{c}{ Stock of human capital } & \multicolumn{2}{c}{ Difference } \\
& Actual $(2010)$ & Theoretical & $\frac{(2)}{(1)}-1, \%$ \\
\hline Algeria & \multicolumn{1}{c}{$(1)$} & \multicolumn{1}{c}{$(2)$} & \multicolumn{1}{c}{$(3)$} \\
Bahrain & 12670555 & 8628558 & -31.9 \\
Egypt & 341700 & 1522687 & 345.6 \\
Iran & 19101817 & 12942838 & -32.2 \\
Iraq & 26019339 & 25885675 & -0.5 \\
Jordan & 4778917 & 4314279 & -9.7 \\
Kuwait & 2388708 & 3697954 & 54.8 \\
Lebanon & 591043 & 1617855 & 173.7 \\
Libya & 1356728 & 1991206 & 46.8 \\
Mauritania & 1796990 & 2353243 & 31.0 \\
Morocco & 194439 & 1362404 & 600.7 \\
Oman & 5074259 & 5177135 & 2.0 \\
Qatar & 1008028 & 1848977 & 83.4 \\
Saudi Arabia & 254767 & 1438093 & 464.5 \\
Sudan & 7389469 & 6471419 & -12.4 \\
Syria & 1654617 & 2157140 & 30.4 \\
Tunisia & 993174 & 1725712 & 73.8 \\
United Arab Emirates & 2326392 & 3235709 & 39.1 \\
Yemen & 2043778 & 2876186 & 40.7 \\
\hline \hline
\end{tabular}

tries. In larger countries with a low percentage of schooled population (Mauritania, Syria, Yemen $)^{25}$ most efforts should be devoted to the improvent of educational attainment rates. In smaller economies, like Bahrain, Qatar and Kuwait, sole education policies are, however, unlikely to lead to a sufficiently large increase of human capital. In those economies education policies must be accompanied with the ones that could attract more human capital from abroad (e.g. Algeria, Egypt or Saudi Arabia). The results also indicate that Iran and Morocco do not need major education or immigration reforms as their stocks of human capital in 2010 are close to what a fully integrated benchmark implies.

\section{Concluding Remarks}

The paper developed a framework that enables the measurement of the degree of economic integration among a group of countries. The objective was to construct an integration benchmark that consists of a steady state equilibrium characterized by free trade and perfect factor mobility. Metrics were then used to measure the distance between the benchmark and the data.

Measurement allowed for a comparison of integration indices over time and across regions. It was performed on the European Union, Latin Amerca and the Middle East,

\footnotetext{
${ }^{25}$ See also Figure A.2 in the Appendix.
} 
the latter being characterized by low intra-regional trade and limited involvement in the global system. We have shown that degrees of integration in 2009 were very close, that of the Middle East being just 2.4\% lower than in EU-15, a benchmark of "complete" integration.

It is a commonly held view that trade is the instrument of choice to achieve greater integration. Regions that demonstrate low intra-regional trade are often concluded to be poorly integrated. The paper casts doubt on the assertion that trade is necessary in order to achieve a high level of economic integration among a group of countries. What we have shown is that international labour and capital mobility can be powerful instruments to achieve integration even in the absence of such trade and of institutional arrangements like free trade agreements and WTO membership.

\section{Acknowledgements}

We thank Fieke Huisman for sharing her valuable insights on integration in the Middle East while at the Dutch Embassy in Tehran. We further thank seminar participants at Erasmus, Michigan and at the CESifo conference on Global Economy (Munich) for their helpful comments and suggestions. The national statistical offices in Lebanon, Oman and United Kingdom have been particularly helpful in providing information on missing data. This paper was partly written while Jean-Marie Viaene was visiting the Department of Economics of the University of Michigan, whose hospitality and financial support under a MITRE grant are gratefully acknowledged. 


\section{A Online Appendix: Data Sources and Methods}

\section{Human Capital}

For the three groups of countries (MENA, ALADI and EU-15), human capital is measured as a total population aged 15 and over with at least completed secondary education ${ }^{26}$ and is obtained from Barro and Lee's data set on educational attainment. The data is on the 5-year interval basis covering the period 1950 - 2010 and is available for all the countries under analysis with the exception of Lebanon and Oman. The data shows a clear exponential growth and we use cubic spline interpolation to obtain annual data. The method is illustrated in Figure A.1 with points representing original figures before interpolation.

Figure A.1: Human capital data interpolation. The example of Iran and Tunisia.
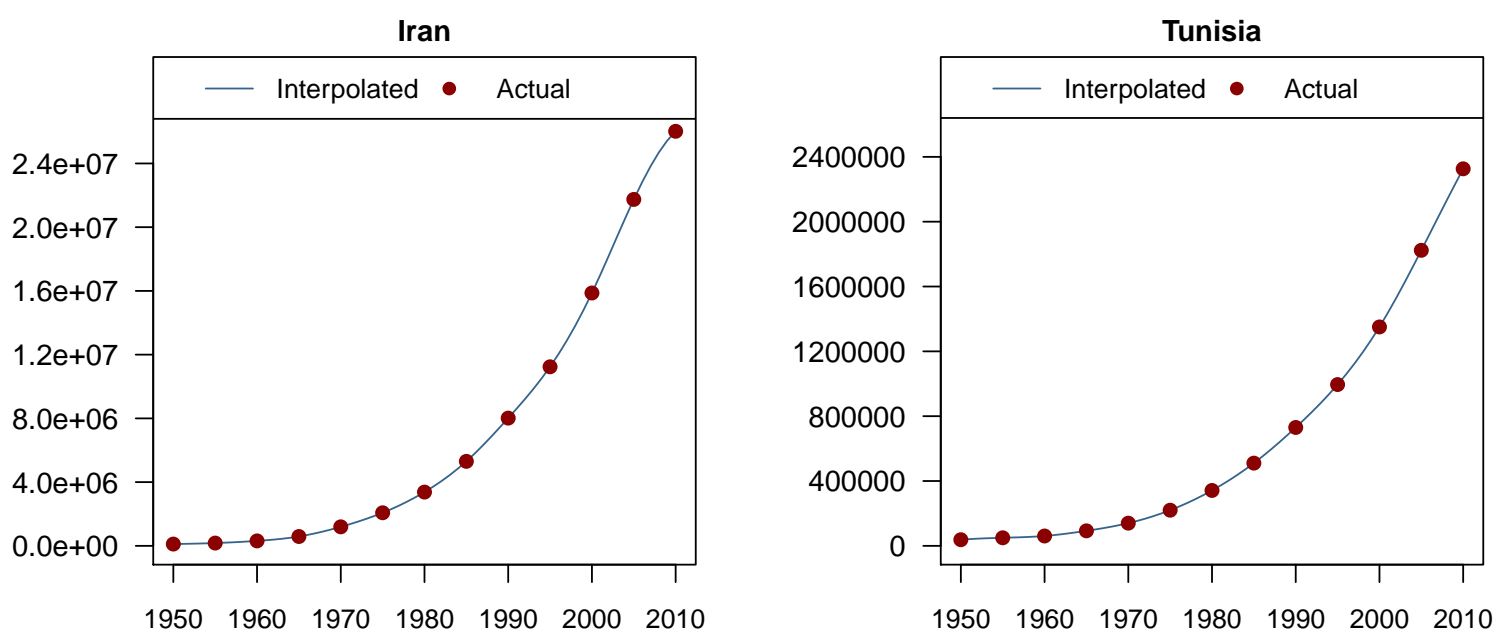

The data for Lebanon were obtained from the household surveys run by its national statistical office. The data were available for years 2004, 2007 and 2009 as a ratio of population with at least secondary schooling to total population. We extrapolated the series by taking the growth rates of the average ratios of human capital to total population over 15 in Jordan and Turkey. To obtain the data for Oman we approximated its ratio of population with a complete secondary education to total population over 15 with the average ratio of Jordan and Saudi Arabia. The data on population aged 15 and over was obtained from the United Nations UNSD Demographic Statistics database. Obtained estimates are comparable to the data on the percentage of expatriate workers in Oman with at least secondary degree averaged with the percentage of Omani nationals with at least secondary degree who are employed in public sector. The data on the latter two

\footnotetext{
${ }^{26}$ We consider the sum of the population aged 15 and over with (i) completed secondary education as the highest obtained education level and (ii) completed or incomplete tertiary education as the highest obtained education level.
} 
indicators is obtained from the national statistical office in Oman ${ }^{27}$. Immigrants make up $28.4 \%$ of Omani population ${ }^{28}$.

Human capital demonstrates a clear exponential growth. In 2010 human capital in MENA constituted 32.5\% (32.3\% Lebanon and Oman excluded) of the total MENA population aged 15 and over. This ratio is higher when for ALADI (38.7\%) and it is even higher for EU-15 (52.04\%). As Figure A.2 suggests around $60 \%$ of adult population in Jordan, Bahrain, Bolivia, Chile have completed at least secondary education. The ratio is lower than $10 \%$ in Sudan, Syria and Mauritania.

Figure A.2: Human capital as a share in total population aged 15 and over.
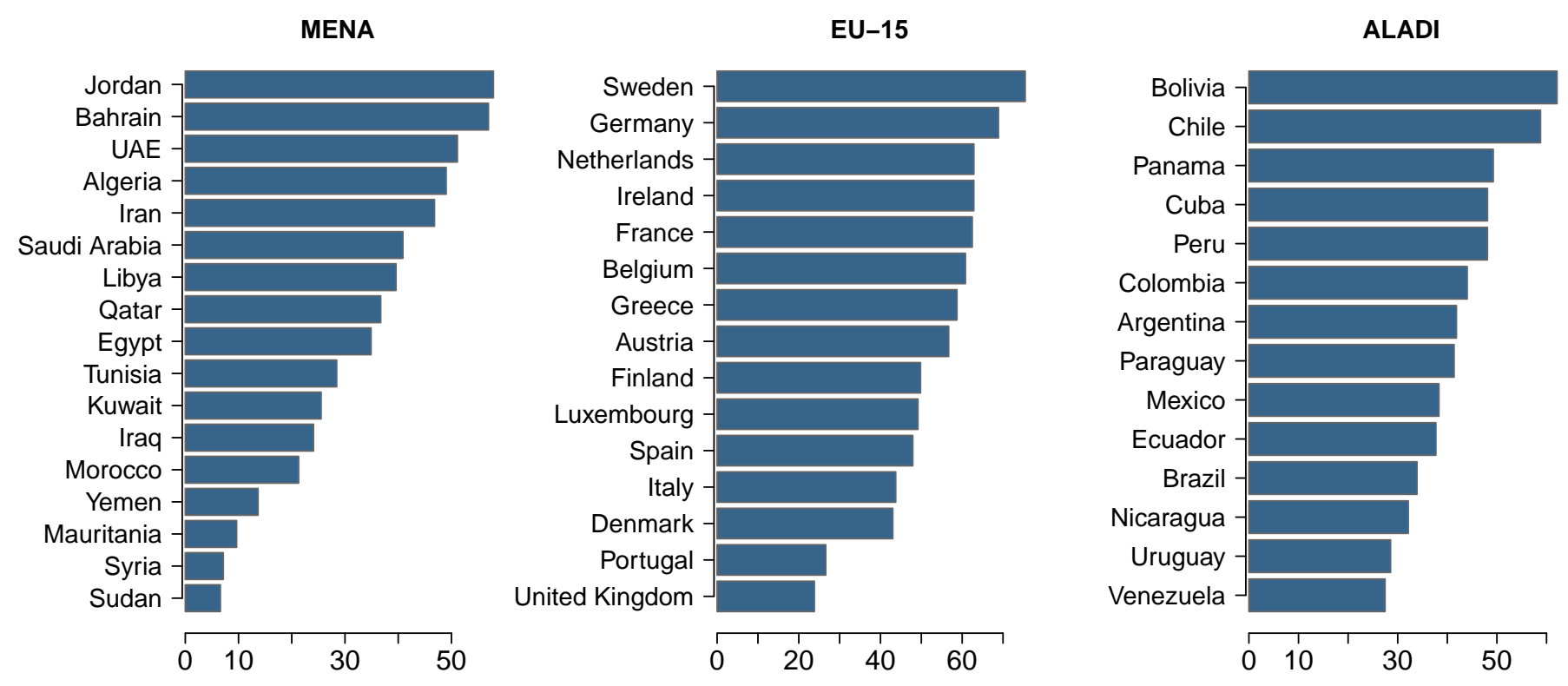

Note: Year 2010.

Source: Barro and Lee (2013).

Regarding EU-15 an element of concern in our research is the fact that the percentage of adults with at least completed secondary education is unrealistically low in the UK (see panel (c) in Figure A.2). This may explain a large drop in our integration measure when output based computation for EU-15 is performed.

\section{Physical Capital}

Data for physical capital in all regions come from Penn World Tables, version 6.2 (PWT 6.2) and cover the period of 1950 - 2004. The data is in constant prices with the base year

\footnotetext{
${ }^{27}$ In $199721.3 \%$ of expatriate workers in Oman had at least secondary education. The percentage is $17.5 \%$ in 2000 and $24.3 \%$ in 2005. Source: Own calculations based on the data from Oman National Statistics.

${ }^{28}$ Source: World Bank Migration and Remittances Factbook 2011.
} 
of 2000. Measurement units are international dollars. Given that this is the most recent capital stock data available, year 2000 became a benchmark reference year for all the real variables included into analysis.

There were two problems associated with the capital stock data in hand. First, the data was available until the year 2004 only or even until 2003 for most of MENA countries. Second, no data was available for Lebanon, Libya and Yemen.

The first above mentioned problem was solved as follows. We computed the total investment $I_{i t}$ in constant 2000 prices at time period $t$ for country $i$ using the real investmentto-GDP ratios available in PWT 6.2. Furthermore, from the inventory rule

$$
K_{i t}=\left(1-\delta_{i t}\right) K_{i t-1}+I_{i t}
$$

we computed depreciation rates $\delta_{i t}$ and by applying a 5 -year moving average we extended the rates until 2009 (see Figure A.3).

Figure A.3: Depreciation rates: the example of Algeria and Mexico.
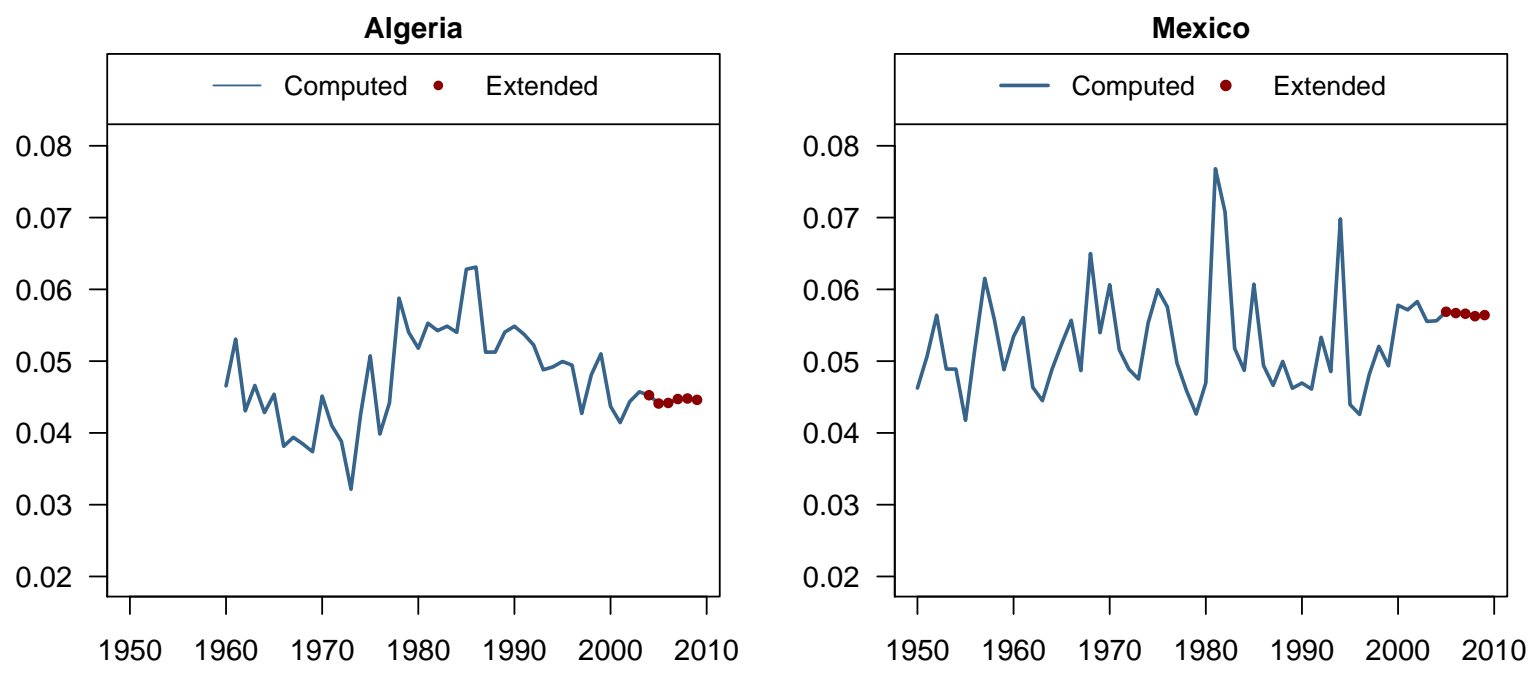

Source: Own calculations based on PWT 6.2.

Capital depreciation rates vary between $3 \%$ for Sudan and $11 \%$ for United Arab Emirates in 2003. The same range of variation remained for estimated depreciation rates in 2009.

PWT 7.0 contains investment-to-GDP ratios in constant 2005 prices until 2009. This allows to compute total investment in constant 2000 prices and extend total real investment $I_{i t}$ from PWT 6.2 to missing years 2004(2005)-2009. Together with the estimated depreciation rates it becomes feasible to obtain an estimate of $K_{i t}$ for $t=2004(2005), \ldots, 2009$ using inventory rule. It is to mention that total real investment in 2000 prices differs between the two versions of PWT by almost a scalar. Growth rates, however, remain almost 
unchanged (see examples in Figure A.4).

Figure A.4: Difference in total real investment as available in PWT 6.2 and PWT 7.0: the example of Libya and Lebanon.
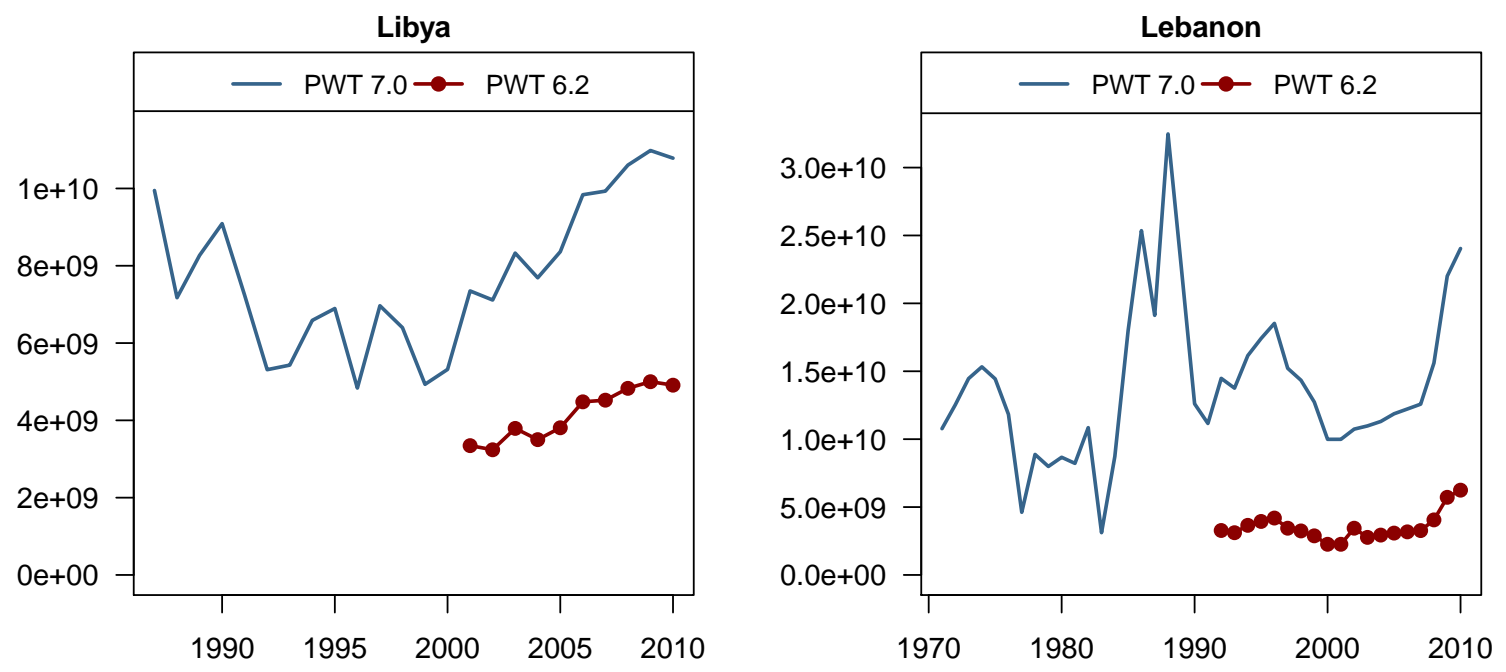

Source: PWT 6.2, PWT 7.0.

To estimate unavailable capital data for Lebanon, Libya and Yemen we employed real investment-to-GDP ratios available in Penn World Tables, version 7 (PWT 7.0). We computed total investment in constant 2000 prices and we extended the series backwards using for Libya the growth rates of gross capital formation in constant prices taken from IMF IFS database and for Yemen using real investment taken from PWT 5.6. As a result total real investment for the whole period 1970-2009 was obtained. Given total real investment initial real capital stock $K_{i 0}$ and depreciation rates $\delta_{i t}$ are sufficient to compute the whole series of capital using the inventory rule. For Lebanon and Yemen $\delta_{i t}$ was estimated as the average depreciation rate of Syria and Jordan and for Libya the average depreciation rate of Tunisia, Morocco, Algeria and Egypt was taken. Initial capital stock was then estimated as

$$
K_{i 0}=Y_{i 0}\left(\frac{1}{n_{i}} \sum_{j=1}^{n_{i}} \frac{K_{j 0}}{Y_{j 0}}\right)
$$

where $t=0$ is the earliest year for which real capital-to-GDP of partner countries is available, $n_{i}$ is the number of partner countries for the country in question and $Y_{i 0}$ is a real output of country $i$ at the initial time period. As in case of $\delta_{i t}$ estimation, Syria and Jordan were taken as partner countries for Lebanon and Tunisia, Morocco, Algeria and Egypt were taken as partner countries for Libya. 


\section{Output}

Output in all country groupings, measured by real GDP, is obtained from PWT 7.0. The data ranges from 1950 to 2009 and is expressed in international dollars to equalize the purchasing power of different currencies and allow for cross-country level data comparison. PWT 7.0 uses the year 2005 as a base year for all constant price variables. We use 2000 as the base year in our study. Hence, to convert the base year of real output to 2000 we find the implicit deflator in 2000 for each of the countries and rescale 2005 constant price series accordingly.

Most ALADI countries, except Cuba, have output data available as of 1950. Output of Cuba is available as of 1970. The situation differs for MENA. Only few countries, namely, Egypt, Iran, Jordan and Morocco have data starting prior to 1955. In 1970, however, 13 (out of 19) MENA countries do have observations leaving out Kuwait, Qatar, Saudi Arabia, United Arab Emirates, Libya and Yemen, series for which start in late 80-ties. The older version of PWT (6.2), however, contains real GDP data for Kuwait, Qatar, Saudi Arabia and UAE as of 1970. We used the growth rates of constant price series taken from PWT 6.2 to extend existing data backwards. Although some degree of discrepancy is present between data published in the two versions of PWT, especially for level data of Saudi Arabia and Qatar (see Figure A.5), the growth rates in overlapping years remain very similar, maintaining the plausibility of estimated data.

Figure A.5: Output data extension for Kuwait, Qatar, Saudi Arabia and UAE.
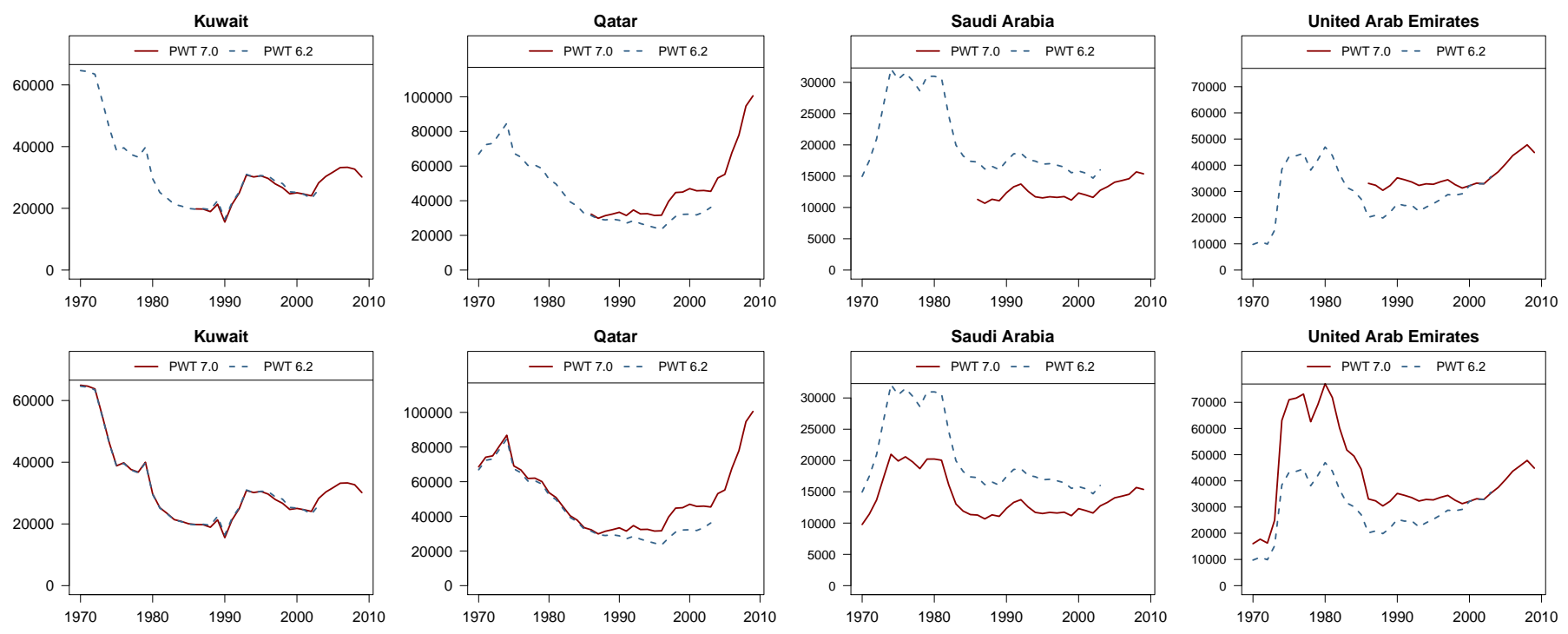

Note: PWT $6.2(7.0)$ is an abbreviation for Penn World Tables, version 6.2 (7.0).

Because Yemen Arab Republic and People's Democratic Republic of Yemen were united in 1990 to form the current Republic of Yemen, most of the international data sources do 
not publish data prior to 1990 for the two former republics separately. The data is neither publicly available on the website of the national statistical authority of Yemen. The oldest version of PWT (5.6), however, contains a joint 1969 - 1989 GDP per capita for Yemen both in current and constant 1985 prices. It therefore becomes possible, similarly as described above, to extend available real output data for Yemen by applying PWT 5.6 growth rates backwards. Although there is some difference in the level of real GDP as published in PWT 5.6 and PWT 7.0 respectively in the common year 1989, it is yet the best estimate we could obtain for Yemen for the period 1970 - 1989 prior to its unification.

To obtain real output data for Libya for 1970 - 1985 we used its GDP in constant prices expressed in local currency units from the International Financial Statistics (IFS) database of IMF. Analogously to the case of Yemen we applied the growth rates backwards to compute the data for missing years.

\section{Average income per capita: MENA and ALADI}

Average income per capita measured as GDP per capita in ALADI countries was 9405.8 international dollars in 2009. Average income per capita in the Middle East on the other hand was more than twice as high amounting to 22618.5 international dollars. ${ }^{29}$ This difference, however, is mainly driven by few rich and small oil-exporting countries, like Qatar, Kuwait and United Arab Emirates. The boxplot in Figure A.6 shows that GDP per capita in Qatar, United Arab Emirates and Kuwait is more than 1.5 interquartile ranges above the third quartile of the GDP per capita distribution in MENA. These countries are therefore pointed out as outliers. ${ }^{30}$ The distribution in ALADI is clearly more homogeneous in the sense that no extreme observations are present. After the exclusion of Qatar, United Arab Emirates and Kuwait MENA and ALADI show indeed very similar average income per capita (10283.3 international dollars in MENA vs. 9405.8 in ALADI, see also the two rightmost graphs in Figure A.6). Analogous conclusions are drawn also from the computation of the population weighted average. In MENA the population weighted average is 8952.7 international dollars and that in ALADI is 10724.8

\footnotetext{
${ }^{29}$ Source: Penn World Tables (PWT) 7.0.

${ }^{30}$ We use the simple interquartile rule to detect outliers. A data point is identified as an outlier if it is above $Q_{3}+1.5 I Q R$, where $Q_{3}$ is the third quartile of the data distribution and $I Q R$ is the measure of the spread of the data around the median defined as the difference between the third and the first quartiles.
} 
Figure A.6: Nominal GDP per capita in ALADI and MENA.
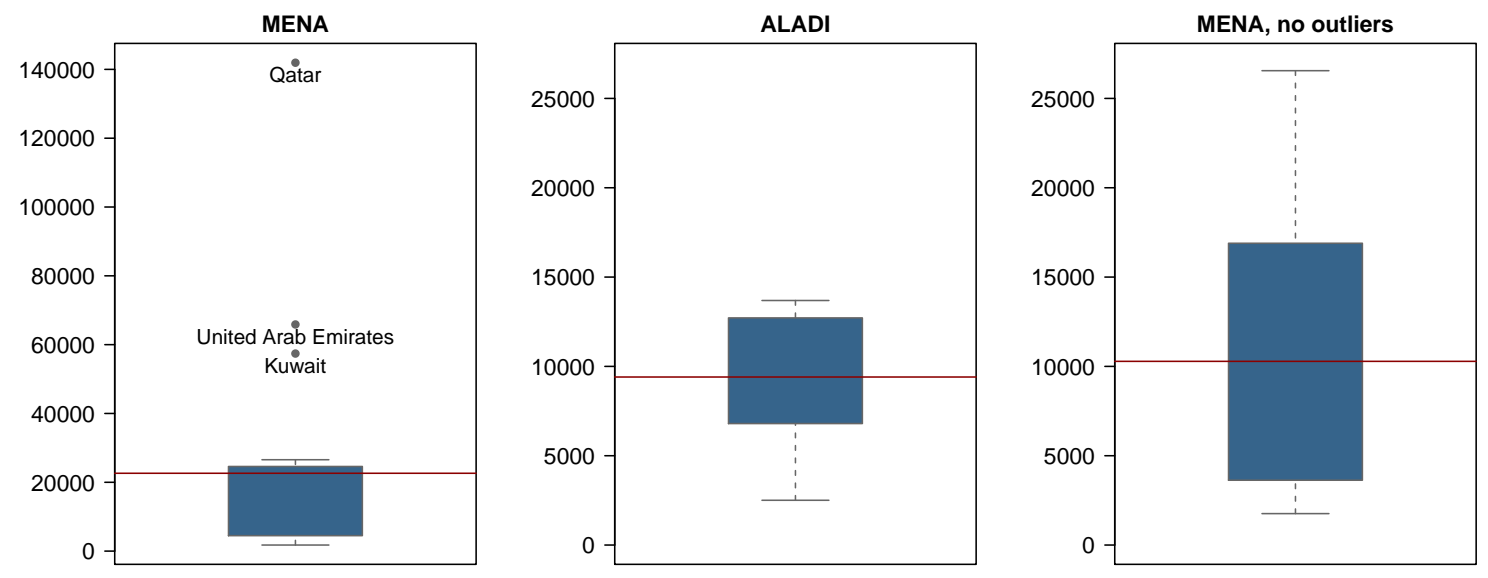

Notes: The leftmost boxplot includes nominal GDP per capita for all the MENA countries. The rightmost boxplot excludes Qatar, United Arab Emirates and Kuwait and displays the distribution of nominal GDP per capita for the remaining 16 MENA countries. Horizontal lines denote sample averages. Year 2009. International dollars.

Source: Penn World Tables 7.0. 


\section{References}

Aït-Sahalia, Y. (2002), "Maximum-Likelihood Estimation of Discretely-Sampled Diffusions: a Closed-Form Approximation Approach," Econometrica, 70(1), 223-262.

Al-Atrash, H. and Yousef, T. (2000), "Intra-Arab Trade: Is It Too Little?" IMF Working Paper.

Barro, R.J. and Lee J.W. (2013), "A New Data Set of Educational Attainment in the World, 1950-2010," Journal of Development Economics, 104, 184-198.

Bernanke, B. (2005), "The Global Saving Glut and the U.S. Current Account Deficit," Sandridge Lecture, Virginia Association of Economics, Richmond (Virginia).

Borjas, G.I. (2001), "Does Immigration Grease the Wheels of the Labor Market?" Brookings Paper on Economic Activity, 1, 69-133.

Bowen, H., Leamer, E.E. and Sveikauskas, L. (1987), "Multicountry Multifactor Tests of the Factor Abundance Theory," American Economic Review, 77(5), 791-809.

Bowen, H.P., Munandar, H. and Viaene, J.-M. (2011), "Are EU Countries less Integrated than US States? Theory and Evidence," Journal of Regional Science, 51(4), 653-677.

Bugamelli, M. and Paterno, F. (2011), "Output Growth Volatility and Remittances," Economica, 78(311), 480-500.

Carrillo-Tudela, C. and A Li, C. (2004), "Trade Blocks and the Gravity Model: Evidence from Latin American Countries," Journal of Economic Integration, 19(4), 667-689.

Caselli, F. and Feyrer, J. (2007), "The Marginal Product of Capital," Quarterly Journal of Economics, 122(2), 535-568.

Dai, J.G. and Harrison, J.M. (1992), "Reflected Brownian Motion in an Orthant: Numerical Methods for Steady-State Analysis," Annals of Applied Probability, 2, 65-86.

Djajić, S., Michael, M. S. and Vinogradova, A. (2012), "Migration of Silled Workers: Policy Interaction between Host and Source Countries," Journal of Public Economics, 96(11), 1015-1024.

Djajić, S. (2014), "Temporary Emigration and Welfare: the Case of Low-Skilled Labor," International Economic Review, 55(2), 551-574.

Ekanayake, E.M. and Ledgerwood, J.R. (2009), "An Analysis of the Intra-Regional Trade in the Middle East and North Africa Region," International Journal of Business and Finance Research, 3(1), 19-29. 
Facchini, G., Mayda, A.M. and Mishra, P. (2011), "Do Interest Groups Affect US Immigration Policy?" Journal of International Economics, 85(1), 114-128.

Findlay, R. and O'Rourke, K.H. (2007), Power and Plenty. Trade, War, and the World Economy in the Second Millennium (Princeton, NJ: Princeton University Press).

Gabaix, X. (1999), "Zipf's Law for Cities: an Explanation," Quarterly Journal of Economics, 114(4), 739-767.

Gabaix, X. and Ibragimov, R. (2011), "Rank-1/2: a Simple Way to Improve the OLS Estimation of Tail Exponents," Journal of Business Economics and Statistics, 29(1), 24-39.

Galor, O. and Stark O. (1990), "Migrants' Savings, the Probability of Return Migration and Migrants' Performance," International Economic Review, 31(2), 463-467.

García, E.C., Navarro Pabsdorf, M. and Gómez Herrera, E. (2013), "The Gravity Model Analysis: an Application on MERCOSUR Trade Flows," Journal of Economic Policy Reform, 16(4), 336-348.

Gourinchas, P.-O. and Rey, H. (2014), "External Adjustment, Global Imbalances, Valuation Effects," in Gopinath, G., Helpman, E. and Rogoff, K. (Eds.), Handbook of International Economics (Amsterdam: Elsevier), Vol IV, 585-645.

Hanson, G.H. (2010), "International Migration and the Developing World," in D. Rodrik and M.R. Rosenzweig (Eds.), Handbook of Development Economics (Amsterdam: North Holland), Vol.5, 4363-4414.

Harrison, J.M. (1985), Brownian Motion and Stochastic Flow Systems (New York: Wiley).

Harrison, E.A. and Rodríguez-Clare, A. (2009), "Trade, Foreign Investment and Industrial Policy," in D. Rodrik and M.R. Rosenzweig (Eds.), Handbook of Development Economics (Amsterdam, North-Holland), Vol. 5, ch. 63.

Harrison, J.M., Williams, R.J. (1987), "Multidimensional Reflected Brownian Motions Having Exponential Stationary Distributions," The Annals of Probability, 15(1), 115137.

Helpman, E. and Krugman, P. (1985), Market Structure and Foreign Trade (Cambridge, MA: MIT Press).

Javorcik, B.S., Özden, Ç, Spatareanu, M. and Neagu, C. (2011), "Migrant Networks and Foreign Direct Investment," Journal of Development Economics, 94(2), 231-241. 
Klein, P. and Ventura, G. (2009), "Productivity Differences and the Dynamic Effects of Labor Movements," Journal of Monetary Economics, 56(8), 1059-1073.

Kugler, M. and Rapoport, H. (2007), "International Labor and Capital Flows: Complements or Substitutes?" Economics Letters, 94(2), 155-62.

Lucas, R.E. (1990), “Why Doesn't Capital Flow from Rich to Poor Countries?” American Economic Review, 80, 92-96.

Mundell, R. (1957), "International Trade and Factor Mobility," American Economic Review, 47, 321-335.

Naufal, G.S. (2011), "Labor Migration and Remittances in the GCC," Labor History, $52(3), 307-322$.

Özden, Ç, Parsons, C.R., Schiff, M. and Walmsley, T.L. (2011) "Where on Earth is Everybody? The Evolution of Global Bilateral Migration 1960-2000," World Bank Economic Review, 25(1), 12-56.

Péridy, N. and Abedini, J. (2008), "The Greater Arab Free Trade Area (GAFTA): an Estimation of Its Trade Effects," Journal of Economic Integration, 23, 848-872.

Revankar, N.S. (1971), "A Class of Variable Elasticity of Substitution Production Functions," Econometrica, 39(1), 61-71.

Riezman, R., Whalley, J. and Zhang, S. (2011), "Distance Measures between Free Trade and Autarky for the World Economy," Economic Modelling, 28, 2000-2012.

Riezman, R., Whalley, J. and Zhang, S. (2013), "Metrics Capturing the Degree to which Individual Economies Are Globalized," Applied Economics 45(36), 5046-5061.

Rivera-Batiz, L.A. and Romer, P.M. (1991), "Economic Integration and Endogenous Growth," Quarterly Journal of Economics, 106(2), 531-555.

Romagnoli, A. and Mengoni, L. (2009), "The Challenge of Economic Integration in the MENA Region: from GAFTA and EU-MFTA to Small Scale Arab Unions," Economic Change and Restructuring, 42(1-2), 69-83.

Uebele, M. (2013), "What Drives Commodity Market Integration? Evidence from the 1800s," CESifo Economic Studies, 59(2), 412-442.

Veestraeten, D. (2008), "Valuing Stock Options when Prices are Subject to a Lower Boundary," Journal of Futures Markets, 28(3), 231-247.

Viaene, J.-M. and Zilcha, I. (2002), "Capital Markets Integration, Growth and Income Distribution," European Economic Review, 46, 301-327. 
Volosovych, V. (2011), "Financial Market Integration over the Long Run: Is there a Ushape?" Journal of International Money and Finance, 30, 1535-1561.

Wilson, S.I. (2003), "A Dynamic General Equilibrium Analysis of Migration and Capital Formation: the Case of Canada," Review of Economic Dynamics, 6(2), 455-481.

World Bank (2004), "The Middle East and North Africa," Investment Report (Washington, D.C.: World Bank).

World Bank (2011), Migration and Remittances: Factbook 2011 (Washington, D.C.: World Bank).

Zhang, L. and Du, Z. (2010), "On the Reflected Geometric Brownian Motion with Two Barriers," Intelligent Information Management, 2(4), 295-298. 